Research Article

\title{
Evaluation of the Floor Acceleration Amplification Demand of Instrumented Buildings
}

\author{
Baofeng Huang $\mathbb{D}^{1,2}$ and Wensheng $\mathrm{Lu}^{3}$ \\ ${ }^{1}$ College of Civil Engineering, Shanghai Normal University, Shanghai, China \\ ${ }^{2}$ College of Civil Engineering, Nanjing Tech University, Nanjing, China \\ ${ }^{3}$ College of Civil Engineering, Tongji University, Shanghai, China \\ Correspondence should be addressed to Baofeng Huang; baofeng@njtech.edu.cn
}

Received 24 May 2021; Accepted 30 July 2021; Published 10 August 2021

Academic Editor: Wei-yao Guo

Copyright (C 2021 Baofeng Huang and Wensheng Lu. This is an open access article distributed under the Creative Commons Attribution License, which permits unrestricted use, distribution, and reproduction in any medium, provided the original work is properly cited.

\begin{abstract}
The floor acceleration amplification (FAA) factor is one of the most critical parameters in computing the equivalent seismic force of nonstructural component (NC). To evaluate the heightwise FAA distribution profile, the recorded acceleration response of the instrumented buildings was analyzed using the California Strong Motion Instrumentation Program (CSMIP) database. The FAA demands for three groups of buildings consisting of reinforced concrete, steel, and masonry buildings were analyzed. In each group, the buildings were classified into four subgroups according to their heights. Parabolic distribution profiles were suggested that could envelop most of the FAA data, as demonstrated by the processed results. An earthquake experience-based importance factor was suggested in terms of the percentage of the enveloped records. The obtained FAAs at the roof were generally larger than those in other levels. The percentile distributions of the roof acceleration amplification (RAA) were computed. The results showed that the roof FAA was underestimated in ASCE 7-16. The magnitudes of the FAA and the RAA correlated to the fundamental period of the building, which was considered by classifying the buildings according to the period ranges. The RAA profile against the period was obtained from a regression analysis. The developed FAA profile is expected to be useful in the seismic design of $\mathrm{NCs}$, and it is expected to be adopted in future code provisions.
\end{abstract}

\section{Introduction}

Nonstructural components (NCs) and systems have been widely used in building structures to provide a suitable function for human habitation. The seismic losses in terms of injury, damage, dollars, and downtime were considerable in the past major earthquakes $[1,2]$. To reduce these losses, the seismic performance of NCs should be enhanced through analytical and experimental studies. The early research progress in the seismic response of NCs and systems was summarized in [3]. Comparing with the structural members, the seismic design and behavior of the NCs have received relatively little attention from practicing engineers and researchers. Simplified procedures for estimating the acceleration demands on the NCs were provided in the current seismic provisions [4-7] where a trapezoidal heightwise peak floor acceleration (PFA) distribution varied from the peak ground acceleration (PGA) at the ground floor to $3.0 \times \mathrm{PGA}$ at the roof. However, the number of stories or the structural configurations of the building were not considered. Consequently, the authors in [8] argued that the suggested PFA in codes may be inadequate for many structures because some factors that significantly affecting the seismic response of NCs were not accounted in the design-oriented methods [9]. The authors in [10, 11] addressed critical comments on the early version of the provisions (see, e.g., [5]). The ratio of the PFA to the PGA, namely, the floor acceleration amplification (FAA), has become a measure to represent the acceleration amplification effect of the main building structure to the PGA. It is an important factor to compute the equivalent seismic force of the NCs $[5,6]$. 
Significant nonstructural damage was observed in the 1964 Alaska earthquake [12] and the 1971 San Fernando earthquake in California [13]. The 1971 San Fernando earthquake, in particular, gave rise to the Hospital Seismic Safety Act in California [14], which established new seismic safety standards for new hospitals, including NCs. The seismic performance of NCs has attracted extensive attention from researchers since the 17 October 1989 Loma Prieta earthquake, in which severe damage to NCs occurred and caused considerable economic losses [15]. Analytical works have been carried out in the literature to investigate the heightwise distribution profile of an FAA. The authors in $[16,17]$ analyzed the seismic response of two instrumented buildings, one with a 30-story reinforced concrete frame and the other with a 60-story steel frame, to the Loma Prieta earthquake, where the largest FAA was 1.81 with the PGAs of $0.21 \mathrm{~g}$ and $0.17 \mathrm{~g}$. The FAAs of 25 instrumented multistory buildings in the 1994 Northridge earthquake ranged between 1.1 and 4.6 [18], and identical trend was addressed by [19] in the same earthquake event. Rodriguez et al. [20] developed a simple first-mode reduced method for estimating the FAA demand of 3-story and 12-story buildings. The calculation procedure was more complicated than that given in the code provisions (e.g., ASCE 7-10 [21]), and its applicability to other buildings with various heights and structural configurations needed further work. Chaudhuri and Hutchinson [22] conducted a nonlinear analytical study of 4-, 8-, 12-, and 16-story steel frames for which the largest FAA was approximately 5.3, appearing in the 4-story rigid frame. Reinoso and Miranda [23] investigated six instrumented tall buildings subjected to five historical earthquakes. Their results indicated that the FAAs were distributed relatively evenly along the building height except for those close to the top stories. In the Loma Prieta (1989) and Northridge (1994) earthquakes, the largest roof FAA was 4.5 [23]. The authors in $[24,25]$ presented new formulas that depended on the building period to improve the accuracy in calculating the FAA demand of the rigid and flexible NCs. To estimate the nonlinear seismic response of NCs in the nonlinear building structures, an approximate response spectrum method was proposed in [26]. The simplified closed-form solution of an FAA correlated to the mode shape as well as fundamental periods of an NC and a main structure. The computational studies of [27] demonstrated that an FAA correlated to the height, damping ratio, and fundamental period of the main building. The largest computed FAA was close to 4.0, which was observed in a two-dimensional single-bay 3-story frame, instead of the 6-, 9-, and 18-story frames. Miranda and Taghavi [28] analyzed the linear and nonlinear responses of buildings to earthquake excitations. Their results indicated that the magnitude of the FAA demand and its heightwise variation closely correlated to vibration period, the lateral resisting system, and the damping ratio of the building structure. Taghavi and Miranda [29] developed a response spectrum method to estimate the FAA demand of multistory buildings that considered the correlations between the modal accelerations and between the ground and modal accelerations. Chaudhuri and Hutchinson [30] performed a nonlinear time history analysis of eight representative flexible and stiff steel moment resisting frames using 25 selected ground motions. For the FAAs in the nonlinear flexible frames with long fundamental periods, the codified profiles were overestimated, while they were underestimated at the lower floor levels in the stiff frames. To estimate the PFA profile, a response spectrum analysis method was proposed in [31] based on the complete quadratic combination rule, where a consistent PFA distribution profile was suggested. The analytical work on reinforced concrete buildings performed by the authors in [32] indicated that the FAA profile was generally enveloped by the suggested profile in ASCE7-16 [6]. The magnitude of the FAA decreased once the nonlinear responses occurred in the model structures. Using the normal stationary random vibration theory, the authors in [33] predicted the median PFA demand of elastic structures under earthquake excitations. Anajafi and Medina [34] indicated that the recommended FAA distribution profile in ASCE 7-16 did not envelop the recorded data in the instrumented buildings. In [35], similar conclusions were addressed regarding the FAA demand in the instrumented buildings. Most recently, a nonlinear dynamic analysis of 16 steel frame buildings was performed by the authors in [36]. A logarithmic polynomial expression for an FAA distribution profile was proposed. This expression accounted for the fundamental vibration period, strength ratio, and normalized height of the building structure. This profile was simplified in ATC-120 [37], for which only three items were involved. Using the suggested expression in $[36,38]$, the roof accelerations of 28 instrumented buildings were investigated, as elaborated in FEMA-58 [39]. The resulting predicted roof accelerations did not perfectly agree with those of the recorded values observed in the 2011 Tohoku earthquake [40]. The component acceleration amplification factor was investigated in $[41,42]$ where floor response spectra were computed on account of the 113 floor motions of the instrumented buildings in California. The results indicated that the magnitude of this factor was generally underestimated in ASCE 7-16 [6], which was confirmed in the shaking table tests [43-45]. Wang et al. [46] summarized the force demands of the NCs regarding the floor response spectra [47]. In the seismic design of various NCs, FAA is a critical parameter $[48,49]$. These studies offered some useful approaches for acquiring reliable FAA for the seismic evaluation of NCs.

The studies in the literature concluded that the actual FAA profiles depended on several features of the main structures such as the structural types, heights, and soil site conditions, and the studies indicated that the current code provisions needed to be revisited. However, most of these studies were based on simulations with numerical models. In this study, the FAA distribution profiles of the instrumented buildings in the California Strong Motion Instrumentation Program (CSMIP) were analyzed in order to develop a representative FAA distribution profile considering several parameters such as PGA, structural types, and heights. The developed profile was expected to be useful for the seismic design and experimental investigation of NCs [50-54] and to be applied in future code provisions. 


\section{FAA in Code Provisions}

Seismic design of NCs has been issued in code provisions in many countries. Among the available codes, the most representative ones are ASCE 7-16 [6], Eurocode 8 [4], and New Zealand code 1170.5 [55]. According to ASCE 7-16 [6], the equivalent horizontal seismic design force applied at the center of gravity (CG) of an NC, $F_{p}$, is calculated as follows:

$$
0.3 S_{D S} I_{p} W_{p} \leq F_{p}=\frac{0.4 S_{D S} a_{p}}{R_{p} / I_{p}}\left(1+2 \frac{z}{h}\right) W_{p} \leq 1.6 S_{D S} I_{p} W_{p} \text {, }
$$

where $I_{p}$ is the component importance factor $\left(I_{p}=1.0\right.$ or 1.5$)$, $W_{p}$ is the weight of the NC, $h$ is the building height, $R_{p}$ is the component response modification factor, and $a_{p}$ is the component acceleration amplification factor $\left(1.0 \leq a_{p} \leq 2.5\right)$. The parameter $0.4 S_{D S}$ is the designed PGA of the main building. $z$ is the elevation of the floor of the NC above grade. In ASCE 7-16, the linear distribution of floor acceleration with height is uncoupled from the acceleration amplification factor $\left(a_{p}\right)$ that is equal to the ratio between the peak acceleration at the CG of an NC to the PFA. This distribution is 1.0 at the first floor and 3.0 at the roof level. In addition, it should be noted that ASCE 7-16 is the only standard in the world that explicitly considers the effect of vertical acceleration on NCs by specifying an equivalent vertical design force. This was beyond the focus of this research, and it will not be elaborated on herein.

Eurocode 8 [4] specifies a design procedure for the seismic design of NCs by taking into account the vibration periods of an NC and the main structure where the NC is located. The equivalent seismic force $F_{a}$ of the NCs is defined as follows:

$$
F_{a}=\frac{S_{a} W_{a} \gamma_{a}}{q_{a}}
$$

where $F_{a}$ is the equivalent seismic force applying at the center of mass in the most unfavorable direction, $W_{a}$ is the weight of the NC, $S_{a}$ is the seismic coefficient pertinent to NCs, $\gamma_{a}$ is the importance factor for which the importance of the NCs is assumed to have the same value as that of the main building, and $q_{a}$ is the behavior factor, which is either 1.0 or 2.0 depending on the typology of the NC being designed. The seismic coefficient $S_{a}$ can be calculated as follows:

$$
S_{a}=\alpha S\left[\frac{3(1+z / H)}{1+\left(1-T_{a} / T_{1}\right)^{2}}-0.5\right], \quad \alpha=\frac{a_{g}}{g},
$$

where $a_{g}$ is the design ground acceleration, $g$ is the gravitational acceleration, $T_{1}$ is the fundamental vibration period of the building in the relevant direction, $S$ is the soil factor, $T_{a}$ is the fundamental period of the NC, $z$ is the elevation of the floor of the NC with respect to the level of the application of the ground motion (normally the ground level), and $H$ is the height of the building. From equation (3), one can find that the magnitude of FAA at the roof level is 2.0, which is smaller than that specified in ASCE 7-16 [6]. Equation (3) takes into account the fundamental periods of the main building and the NCs because significant amplifications are expected in the component acceleration demands if the period of an NC is close to or equal to the fundamental period or any higher modal period of the main building $[41,42]$. If in doubt, the designer may assume that the $\mathrm{NC}$ is tuned to the period of the main building.

In the New Zealand seismic design code [55], the design response coefficient $C_{p}\left(T_{p}\right)$ for an NC supported at level $i$ of a structure is the horizontal acceleration coefficient at the floor level of the main structure where the NC is located. It is computed as follows:

$$
C_{p}\left(T_{p}\right)=C(0) C_{H i} C_{i}\left(T_{p}\right),
$$

where $C(0)$ is the site hazard coefficient at $T=0$, which corresponds to the PGA, $C_{H i}$ is the floor height coefficient at level $i, T_{p}$ is the fundamental vibration period of the $\mathrm{NC}$, and $C_{i}\left(T_{p}\right)$ is the spectral shape factor of the NC. The floor acceleration coefficient at level $i, C_{H i}$, is computed from equations 5, (6), or (7). For elevations that satisfy the height limitations of more than one condition listed below, the lesser value of $C_{H i}$ is used.

$$
\begin{aligned}
& C_{H i}=1+\frac{h_{i}}{6} \quad \text { for } h_{i}<12 \mathrm{~m}, \\
& C_{H i}=1+\frac{10 h_{i}}{h_{n}} \quad \text { for } h_{i}<0.2 h_{n}, \\
& C_{H i}=3.0 \text { for } h_{i} \geq 0.2 h_{n},
\end{aligned}
$$

where $h_{i}$ is the elevation of the story level of the NC and $h_{n}$ is the distance between the base and the uppermost seismic weight or mass of the structure. $C_{H i}$ is taken the same as the ground floor level for levels below the ground floor level. The spectral shape coefficient, $C_{i}\left(T_{p}\right)$, is the ordinate of spectral acceleration corresponding to $T_{p}$. The ordinates of the spectral shape factor of the NC are given as follows:

$$
\begin{aligned}
C_{i}\left(T_{p}\right) & =2.0 \quad \text { for } T_{p} \leq 0.75 \mathrm{~s} \\
& =0.5 \text { for } T_{p} \geq 1.5 \mathrm{~s} \\
& =2\left(1.75-T_{p}\right) \quad \text { for } 0.75 \mathrm{~s}<T_{p}<1.5 \mathrm{~s} .
\end{aligned}
$$

From equations (5) to (8), one can observe that New Zealand code suggests the identical heightwise distribution of the FAA with Eurocode 8. However, a different method that accounts for the fundamental period of the NC is given in this code.

Almost all the current code provisions for FAA employ linear or bilinear distribution profiles using the normalized height $(z / h)$ as a parameter. The FAA calculation methods specified by different code provisions have been summarized in [43]. For these methods, the value of the FAA ranges from 1.0 at the grade to 4.0 at the roof. The peak FAA ranges from 2.0 to 4.0. The resulting FAA distribution profiles in some code provisions are plotted in Figure 1. From this figure, it was observed that the FAAs used in the earlier version of the codes were conservative. The largest FAA was 4.0 in NEHRP 


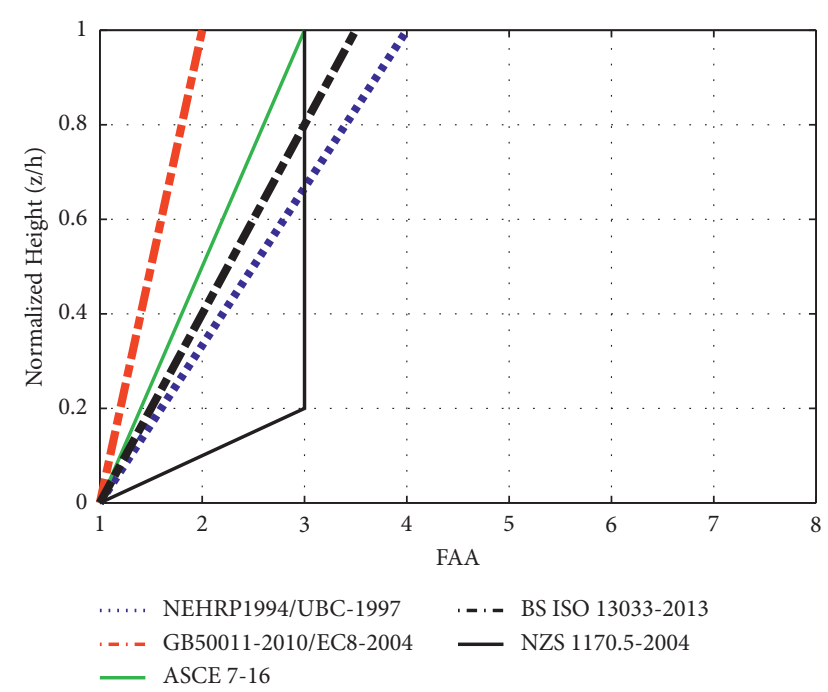

Figure 1: FAA in the current code provisions (after [56]).

1994 [5] and UBC 1997 [56, 57]. Then, based on extensive amount of analytical work conducted, the magnitude of FAA was reduced in the recent code provisions, including ASCE 7-16 [6] and Eurocode 8 [4]. In the current codes, the general suggested value for FAA is 3.0 at the roof level. It was noted that almost all the suggested FAAs were based on the pioneer analytical studies of [58-60] in which the recorded floor acceleration responses in the instrumented buildings were processed by a statistical approach. The structural types and fundamental vibration period were not considered. Therefore, the FAA profiles that were developed in the study might not be fully representative. Accordingly, it was necessary to reanalyze this recorded data and many other data sets measured after this study with consideration of these two parameters.

\section{Analysis Method}

3.1. Building Height Classification. The influence of the building height on the magnitude of the FAA is not considered in the current code provisions because the elevation of the NCs $(z)$ is normalized by the overall height of the building $(h)$. Previous studies have found that the largest magnitude of the FAA in a building often appears at the roof level $[32,56,58,59]$. In addition, because of the whiplash effect, tall buildings can generate somewhat larger FAAs compared with lowrise buildings subjected to the same earthquake excitation [43]. Consequently, the height of a building should be classified before processing the distribution profile of the FAA along the normalized height $(z / h)$. In terms of the number of stories, according to the classification adopted in the CSMIP database, buildings can be categorized as lowrise (1 to 6 stories), midrise (7 to 12 stories), and highrise (more than 13 stories). Preliminary analytical results have shown that the magnitudes of the FAA are almost the same in buildings from 1 to 13 stories, and it is difficult to find a consistent trend to describe the heightwise distribution profile. Furthermore, modern building design and construction technologies have developed significantly in the past two decades. Accordingly, a more qualified classification method than the current method adopted in the CSMIP database is needed. For example, in [60], the number of stories larger than 15 was regarded as one category. This method sounded reasonable but it required further extensive statistical analysis of the height of the existing buildings. Based on the data mining analysis of the building heights worldwide, a new height classification standard was proposed by the Emporis company (https://www.emporis.com), as shown in Table 1. According to this classification, the category of midrise was removed from the traditional standard mentioned above and the new categories of skyscraper, supertall, and megatall were added. In the new standard, the corresponding height levels are 0 to $35 \mathrm{~m}, 35$ to $100 \mathrm{~m}, 100$ to $300 \mathrm{~m}, 300$ to $600 \mathrm{~m}$, and larger than $600 \mathrm{~m}$, for lowrise, highrise, skyscraper, supertall, and megatall buildings, respectively. This standard was followed in processing the FAA distribution profiles in the instrumented buildings with various height levels.

In addition to the height standard, the height limit of a building was determined by its structural type. In many codes for the seismic design of building structures, a height limit is usually recommended for each structural type. Accordingly, a structural type classification in terms of the building materials was applied. The resulting categories were concrete, steel, and masonry buildings.

3.2. Earthquake Records. In the CSMIP database (https:// www.strongmotioncenter.org), buildings with valid records for floor and ground motions were accounted and analyzed. In total, there were 192 buildings, consisting of 72 concrete buildings, 96 steel buildings, 15 masonry buildings, and 9 timber buildings. The number of the earthquake records of interest was 1055. To distinguish the magnitude of the peak ground accelerations (PGAs), the earthquake intensity level was classified in terms of the PGA in [61]. The PGAs were $0.035,0.1$, and $0.2 \mathrm{~g}$, for the frequent (63\% in 50 years), basic (10\% in 50 years), and rare earthquakes ( $2 \%$ in 50 years) (Table 2). The expected seismic responses of the building were elastic, elastoplastic, and plastic, which resulted in the variation of the corresponding floor responses [61], especially the FAAs. Accordingly, there were four earthquake groups, and the groups had 812, 172, 45, and 26 corresponding records (Table 2). Consequently, the statistical results for the buildings with PGAs of less than $0.1 \mathrm{~g}$ were more reliable than those with PGAs larger than $0.1 \mathrm{~g}$. All of the instrumented buildings were lower than $300 \mathrm{~m}$. Most of the concrete and steel buildings were lowrises and highrises, while all of the instrumented masonry and timber buildings were lowrises. The amount of the skyscrapers were limited, so the obtained FAAs might not represent the general properties of these buildings. There were no records of the supertall and megatall buildings. Therefore, for the FAAs in the supertall and megatall buildings, a specific floor acceleration response analysis was required to obtain qualified heightwise distribution profiles [56]. The seismic isolated buildings were not analyzed because their floor acceleration 
TABLE 1: Building height classification.

\begin{tabular}{lcc}
\hline Classification & Height $(\mathrm{m})$ & Story \\
\hline Lowrise & $\leq 35$ & $<12$ \\
Highrise & $35-100$ & $12-39$ \\
Skyscraper & $100-300$ & $>40$ \\
Supertall & $300-600$ & NA \\
Megatall & $>600$ & NA \\
\hline
\end{tabular}

Note. "NA" denotes that no data were available.

TABle 2: Amounts of buildings and earthquake records.

\begin{tabular}{|c|c|c|c|c|c|c|}
\hline \multirow{2}{*}{ Building type } & \multirow{2}{*}{ Height level } & \multirow{2}{*}{ \# Building } & \multicolumn{4}{|c|}{ Earthquake record } \\
\hline & & & PGA $\leq 0.035$ & PGA $0.035-0.1$ & PGA $0.1-0.2$ & PGA $>0.2$ \\
\hline \multirow{3}{*}{ Concrete } & Lowrise & 50 & 224 & 55 & 15 & 10 \\
\hline & Highrise & 20 & 85 & 27 & 7 & 5 \\
\hline & Skyscraper & 2 & 5 & NA & NA & NA \\
\hline \multirow{3}{*}{ Steel } & Lowrise & 57 & 237 & 44 & 9 & 6 \\
\hline & Highrise & 34 & 113 & 17 & 7 & NA \\
\hline & Skyscraper & 5 & 19 & 5 & 1 & NA \\
\hline Masonry & Lowrise & 15 & 82 & 19 & 5 & 2 \\
\hline Timber & Lowrise & 9 & 47 & 5 & 3 & 1 \\
\hline \multicolumn{2}{|c|}{ Total } & 192 & 812 & 172 & 47 & 24 \\
\hline
\end{tabular}

Note. "NA" denotes that no data were available.

responses were considerably reduced compared with those without base isolation measures.

In each earthquake record, three components that comprised two horizontal motions and one vertical motion were observed. Only horizontal components were processed in this study to evaluate the corresponding code provisions particularly in ASCE 7-16. In fact, each earthquake generated two FAA profiles in a building structure in two horizontal directions. The direction with a larger magnitude of FAA was considered conservatively.

3.3. Expressions for FAA Distribution. The linear distribution profile of the FAA could envelop a considerable amount of the measured data points along the building height. The linear profile achieved the maximum value at the roof level, which was consistent with the data measured in most of the instrumented buildings. However, for the stories near the ground and for other levels, there were still many data points that were not enveloped by the linear profile in the code provisions. Therefore, it was necessary to develop a more reliable profile to represent the fundamental dynamic properties and to envelop most of the recorded FAA data. Statistical studies have been performed for this purpose $[30,60,62]$. Fathali and Lizundia [60] suggested a nonlinear distribution profile based on a regression analysis, shown as follows:

$$
F A A=1+\alpha\left(\frac{z}{h}\right)^{\beta}
$$

where $\alpha$ is a velocity factor that was used to determine the heightwise incremental velocity and the value of the roof acceleration amplification (RAA) of the profile and $\beta$ is a shape factor that was used to determine the geometric shape of the profile. When $\alpha=2.0$ and $\beta=1.0$, equation (9) became identical to the profile suggested in ASCE 7-16 [6]. In fact, the shape factor, $\beta$, had a function for enveloping the data points. Less FAA data were enveloped with the increasing magnitude of $\beta$. When $\beta>1.0$, the resulting FAA enveloped a smaller amount of the data points in the lower stories of the building.

Saldana and Terzic [36] carried out a campaign of nonlinear time history analysis of 3-, 6-, 12-, and 16-story buildings. A logarithmic polynomial expression of FAA was developed considering fundamental period $\left(T_{1}\right)$, strength ratio $(S \geq 1)$, and normalized height $(z / h)$ of a building.

$$
F A A=\operatorname{Exp}\left(a_{0}+a_{1} T_{1}+a_{2} S+a_{3} \frac{z}{h}+a_{4}\left(\frac{z}{h}\right)^{2}+a_{5}\left(\frac{z}{h}\right)^{3}\right)
$$

where $a_{i}(i=0-5)$ is the coefficient of the FAA obtained from the regression analysis, as listed in Table $3 . a_{5}$ is set to 0 for the 3 - and 6-story buildings. $S=1.0$ when the building behaves elastically. Equation (10) shows the seismic analysis results of 16 braced steel frames buildings, namely, for a special concentrically braced frame (SCBF) and a buckling restrained braced frame (BRBF) [63]. El Ezz et al. [38] discussed the RAA with equation (10) based on the instrumented data in ATC-120 [37], which was a subset of the CSMIP database. Its applicability to other buildings such as concrete, masonry, and timber buildings with various structural configurations and heights needs further study.

In ATC-120 [37], a simplified version of equation (10) was recommended neglecting the strength ratio of the building. 
TABLE 3: Coefficients for FAA [36].

\begin{tabular}{lccccccc}
\hline $\begin{array}{l}\text { No. of } \\
\text { stories }\end{array}$ & $\begin{array}{c}\text { Brace } \\
\text { type }\end{array}$ & $a_{0}$ & $a_{1}$ & $a_{2}$ & $a_{3}$ & $a_{4}$ & $a_{5}$ \\
\hline \multirow{2}{*}{3,6} & SCBF & 1.152 & -0.469 & -0.0387 & -0.043 & 0.473 & 0.000 \\
& BRBF & 0.919 & -0.295 & -0.042 & -0.247 & 0.426 & 0.000 \\
\hline \multirow{2}{*}{12,16} & SCBF & 0.628 & -0.172 & -0.046 & 3.517 & -8.506 & 5.533 \\
& BRBF & 0.929 & -0.191 & -0.057 & 1.667 & -4.596 & 3.059 \\
\hline
\end{tabular}

$$
F A A=1+a_{1} \frac{z}{h}+a_{2}\left(\frac{z}{h}\right)^{10},
$$

where $a_{1}=1 / T_{1} \leq 2.5, a_{2}=\left[1-\left(0.4 / T_{1}\right)^{2}\right]>0$, and $T_{1}$ is the approximate fundamental period, which could be computed in accordance with ASCE 7-16 [6] as follows:

$$
T_{1}=C_{t} H^{x}
$$

where $C_{t}$ is a coefficient related to the structural type. The corresponding values of $C_{t}$ for the concrete, steel, and masonry buildings are $0.0466,0.0724$, and 0.0488 , respectively. The corresponding $x$ values are $0.90,0.80$, and 0.75 , respectively. Among the three suggested expressions in equations (9)-(11), equation (11) is concise, and it accounted for the fundamental period of the main building.

To compare the reliability of the three expressions for FAA, the recorded FAAs in the lowrise steel buildings from the CSMIP database are plotted as shown in Figure 2. For the PGA $<0.035 \mathrm{~g}$, the main building is supposed to be elastic under this level of earthquake excitation. In general, the height of a 6-story lowrise building is about $18 \mathrm{~m}$. With equation (12), its approximate fundamental period is $0.73 \mathrm{sec}$. Accordingly, the two factors in equation (9) could be found in [60], namely, $\alpha=1.52$, and $\beta=1.57$. The resulting FAA is shown in Figure 2, where the magnitude of the FAA is smaller than that of the ASCE 7-16 [6]. The FAA profiles of the 6-story steel buildings were plotted using the suggested coefficients listed in Table 3 [36]. The strength ratio $(S)$ was set to be 1.0 because these buildings behaved elastically under the PGA $<0.035 \mathrm{~g}$. From Figure 2, one can find that the resulting profiles were generally larger than those suggested by [60]. This was particularly true at the region for the normalized height, $z / h<0.70$. At the ground level, the magnitudes of the FAA were 2.16 and 1.93 for the SCBF and BRBF buildings, respectively. However, theoretically, these two values should have been 1.0. At the roof level, the corresponding FAAs were 3.32 and 2.32. Both were different from that (3.0) given in ASCE 7-16 [6]. For the 6-story steel building, the coefficients in equation (11) [37] were $a_{1}=1 / T_{1}=1 / 0.73=1.37<2.5$ and $a_{2}=\left[1-\left(0.4 / T_{1}\right)^{2}\right]=\left[1-(0.4 / 0.73)^{2}\right]=0.70>0$. The resulting FAA profile seemed to increase linearly when $z / h$ was in the range from 0 to 0.8 and then to increase nonlinearly when $z / h>0.8$ (Figure 2 ). This profile was generally close to that suggested by [60]. These FAA profiles were developed from the straightforward regression analysis without considering the amount of the data points being enveloped. The FAA profile of [60] enveloped the least amount of data, while that of SCBF [36] enveloped the most data points.

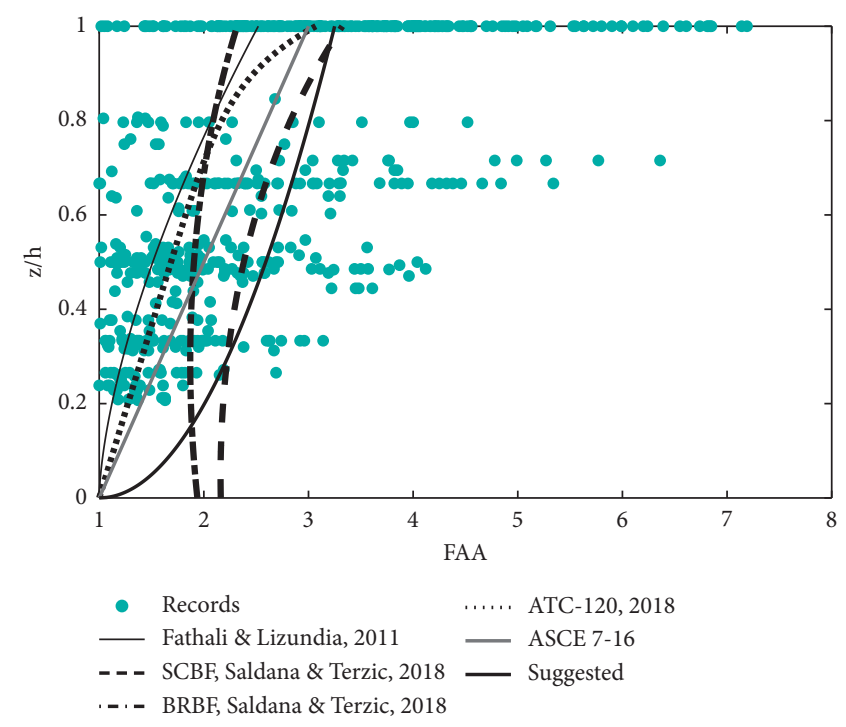

Figure 2: Comparison of the FAA expressions.

However, the latter did not converge to 1.0 at the ground level. Therefore, a new FAA distribution profile needed to be developed based on the existing profiles shown in Figure 2.

Among the FAA profiles in literatures $[6,36,37,60]$, the expression in [60] could be conveniently employed to envelope the data points by adjusting the velocity and shape factors $(\alpha$, and $\beta)$. A parametric analysis indicated that $\beta=0.5$ was a good estimation. The other factor $(\alpha)$ could be acquired through a nonlinear least square data fitting analysis with Matlab [64]. The resulting FAA was represented with equation (13), and it was explored because it is an appropriate improvement to the linear code profile.

$$
F A A=1+\alpha\left(\frac{z}{h}\right)^{0.5}
$$

The resulting distribution profile was a parabola, as shown in Figure 2, for which the velocity factor was $\alpha=2.25$. This could be adjusted with respect to the building types and the quantity of the data points being enveloped. Equation (13) was applied to perform the regression analysis described in the following text.

To provide a graded safety margin for the building owners, three regressed parabolas that enveloped 65\%, 75\%, and $85 \%$ of the data set were given along with the fitted (bestfit) curve (thick solid line in Figure 2) with 95\% confidence bounds. These curves offered decision-making alternatives to the building owners with consideration of the economic affordability. Because more data points were enveloped, the resulting magnitude of the FAA was larger, which corresponded to the equivalent seismic force (e.g., equation (1)). In the roof level, the FAA achieved a peak value that was much larger than that in the lower stories. The percentile analysis method was employed in order to provide a representative value for each type of building under a certain PGA level. 


\section{FAA Distribution Profile}

4.1. Concrete Buildings. The FAAs in the concrete buildings are shown in Figure 3, and the corresponding velocity factors are listed in Table 4. In the lowrise buildings, most of the records appeared for the normalized height $(z / h)$ larger than 0.2 . When the PGA $<0.2 \mathrm{~g}$ (Figures $3(\mathrm{a})-3(\mathrm{c})$ ), the ASCE 716 [6] enveloped the lowest amount of the records, especially at the locations where the magnitude of $z / h$ ranged from 0.2 to 0.8 . It had a relatively good estimation when the PGA was between $0.1 \mathrm{~g}$ and $0.2 \mathrm{~g}$, and when the differences between the fitted and ASCE 7-16 suggested profiles are the lowest (Figure 3(c)). When the PGA $>0.2 \mathrm{~g}$ (Figure 3(d)), the resulting FAA was reduced because of the nonlinear response of the main structure, while the ASCE 7-16 became conservative. The fitted profile was identical to the $65 \%$ enveloping profile when the PGA $<0.1 \mathrm{~g}$, which was not a damageable earthquake in many seismic codes $[4,6,61]$. The velocity factor was reduced with the increasing PGA (Table 4). It is noted that when PGA is close to $0.2 \mathrm{~g}$ or larger, nonlinear response will be induced in many buildings. However, the nonlinearity of the instrumented main building is not the focus of this research because whenever the building behaves linearly or nonlinearly, the resulting FAA distribution profile could be obtained from the instrumented building.

The FAA in the highrise concrete buildings (Figures 3(e)-3(g)) had a similar trend, but its magnitude varied more apparently than that in the lowrise buildings. Unlike the records in the lowrise buildings, the obtained FAA records were more evenly distributed along the height of the building. ASCE 7-16 had a relatively good estimation in PGA $<0.1 \mathrm{~g}$ (Figures 3(e) and 3(f)) on the roof of the building. However, a considerable amount of records were not enveloped in the locations where the $z / h<0.7$. It was much more conservative as the PGA $>0.1 \mathrm{~g}$ (Figures $3(\mathrm{~g}$ ) and $3(\mathrm{~h})$ ), and some records were missed for the lower stories, while too many records were estimated for the roof, especially in the scenario of PGA $>0.2 \mathrm{~g}$ (Figure $3(\mathrm{~h})$ ). The 65\%-85\% envelopment converged into a line due to limited data. For the same earthquake level, the magnitude of the velocity factor in the highrise buildings was generally smaller than that of the lowrise buildings (Table 4). It is noted that the observed data points of FAA $<1.0$ were not considered and are shown in Figure 3 and in the rest of this study because they do not contribute to the expressions in the code provisions and literatures (see, e.g., $[4,6,36,55,60])$.

In the skyscrapers, only the FAA records with the PGA $<0.035 \mathrm{~g}$ were obtained. For this earthquake level, the global structure behaved linearly. The distribution profile of ASCE 7-16 [6] was close to the fitted distribution profile. However, these two profiles enveloped fewer records than those of the 65\%-85\% enveloped profiles.

Among the three types of the FAA distribution profiles, ASCE 7-16 apparently skipped the records in the lower stories, while they were considered in the fitted and the $65 \%-$ $85 \%$ enveloped profiles. The designers of interest had the priority of choosing the velocity factor for the amount of the historical records to be applied. In the roof level, the suggested FAA was too conservative for the PGA $>0.1 \mathrm{~g}$.

4.2. Steel Buildings. The recorded FAA data are plotted in Figure 4 . The velocity factors of the fitted and 65\%-85\% envelopes are listed in Table 5. In the lowrise steel buildings, the trends of the three types of the distribution profiles were similar to those in the lowrise concrete buildings. The ASCE 7-16 suggested profile enveloped the least records in the PGA $<0.1 \mathrm{~g}$ (Figures $4(\mathrm{a})-4(\mathrm{c})$ ). It had a good estimation for the roof as PGA $<0.035 \mathrm{~g}$, but a large amount of data in the lower stories were skipped (Figure 4(a)). The fitted profile enveloped less data than did ASCE 7-16 near the roof when PGA $>0.035 \mathrm{~g}$ (Figures 4(b)-4(d)), indicating that the seismic safety of the NCs could be secured even though the resulting FAAs in the other stories were smaller. The ASCE 7-16 profile seemed conservative at PGA $>0.2 \mathrm{~g}$, and about $95 \%$ of the records were enveloped (Figure 4(d)). The velocity factor was reduced with the increasing value of the PGA (Table 5).

In the highrise buildings, the resulting fitted profile was identical to the $65 \%$ envelopment (Figures $4(\mathrm{e})-4(\mathrm{~g})$ ). The suggested FAA of ASCE 7-16 was larger than the fitted and $65 \%$ envelopes for almost the whole height of the building at PGA $>0.035 \mathrm{~g}$ (Figures 4(f) and $4(\mathrm{~g})$ ). No data were observed at PGA $>0.2 \mathrm{~g}$. However, the magnitude of the FAA was reduced because of the further nonlinear response of the main building. Consequently, ASCE 7-16 had a conservative estimation. The velocity factor was reduced in the fitted and $85 \%$ profiles. A slight increase appears in the $65 \%$ and $75 \%$ envelopments at the PGA ranging from $0.035 \mathrm{~g}$ to $0.2 \mathrm{~g}$ (Table 5).

In the skyscrapers, there were more available records than those for the concrete buildings (Figures $4(\mathrm{~h})-4(\mathrm{j})$ ). The fitted and $65 \%$ enveloped profiles were identical. At PGA $<0.035 \mathrm{~g}$, the ASCE 7-16 formula estimated the resulting FAA with relatively good accuracy (Figure $4(\mathrm{~h})$ ), while the FAA was overestimated at PGA $>0.035 \mathrm{~g}$ (Figures 4 (i) and $4(j)$ ). The velocity factor generally followed the same trend to that of the concrete building. It was reduced with the increasing magnitude of the PGA (Table 5).

Comparing with the ASCE 7-16 suggested FAA profile, the fitted profiles and the percentage-based profiles made full use of the records. There was still some flexibility in determining the amount of records to be applied according to the affordability of the decision makers. The records in the five skyscrapers were not abundant enough to acquire a representative distribution profile. More records would be needed to enlarge the database.

4.3. Masonry Buildings. Fifteen masonry buildings were instrumented in the database. They were all lowrise buildings. The tallest building was an 11-story residential building $(24.3 \mathrm{~m})$ in Oakland, California, USA. The obtained FAA records are plotted in Figure 5, and the corresponding velocity factors are listed in Table 6. At the roof level, the FAA profile was approximately estimated in ASCE 7-16 at PGA $<0.1 \mathrm{~g}$ (Figures 5(a) and 5(b)). For the other stories, however, 

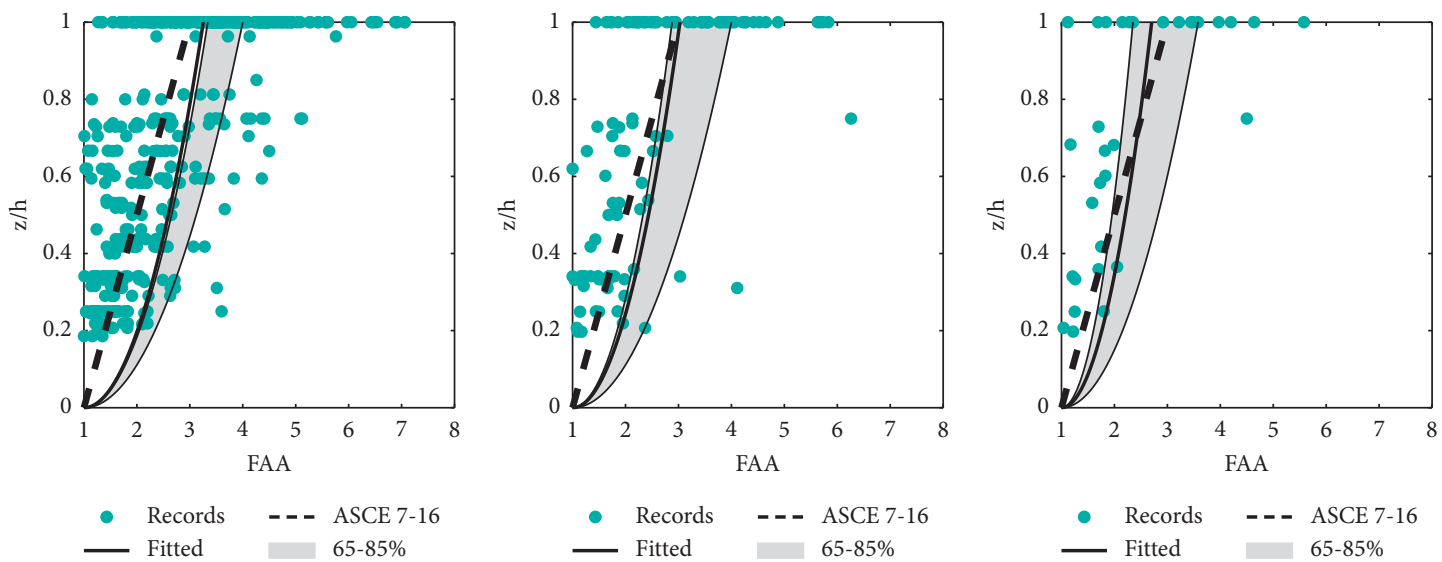

(a)
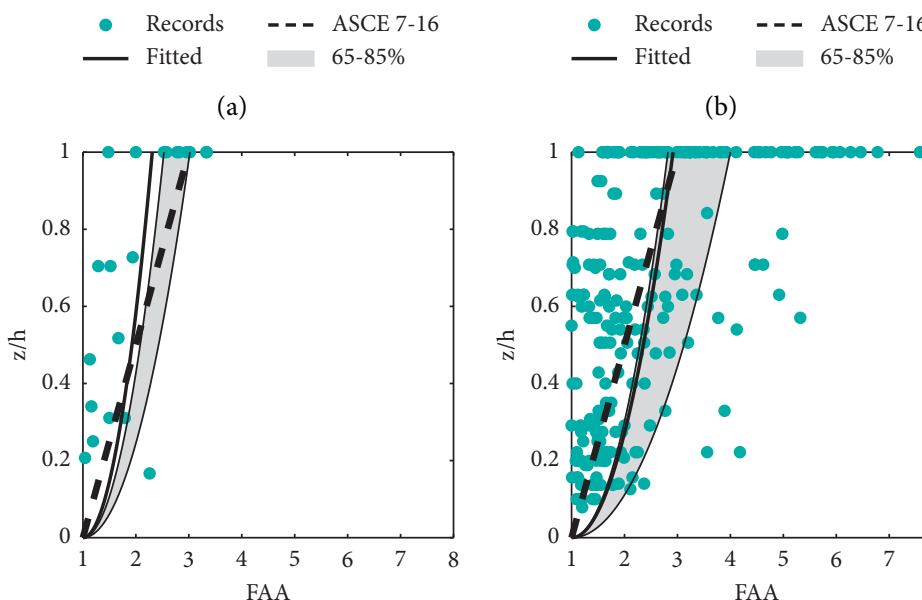

(b)

(c)
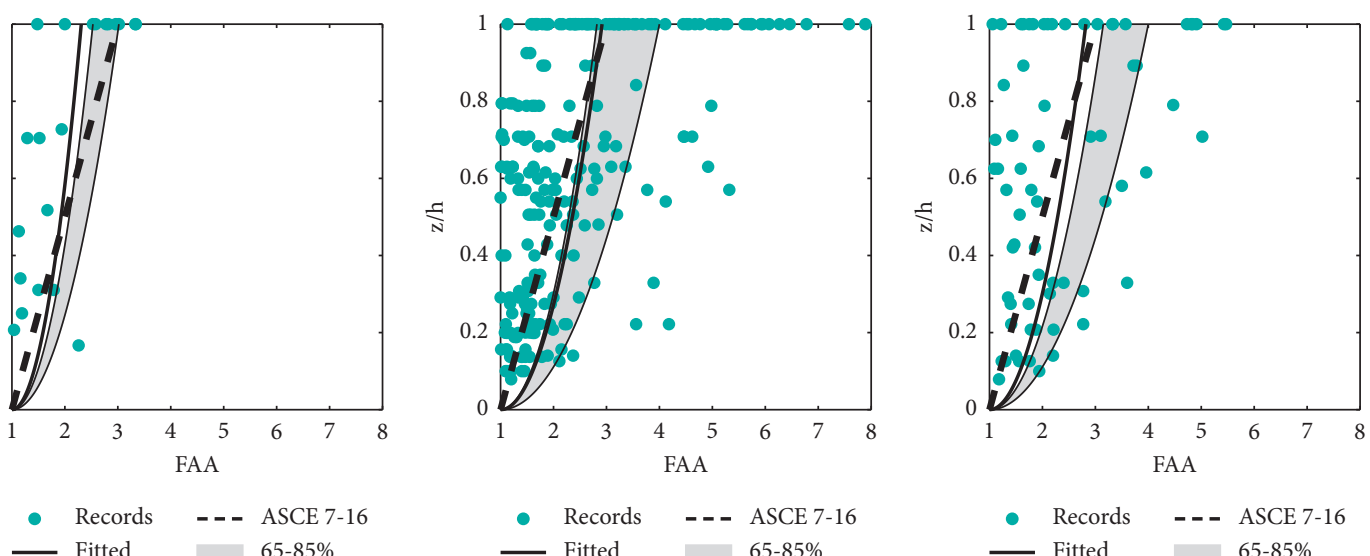

- Records - - - ASCE 7-16

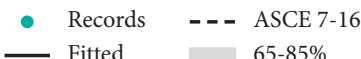

(d)

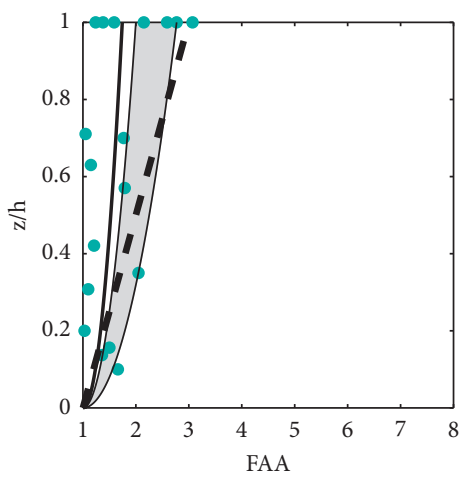

(e)

(f)

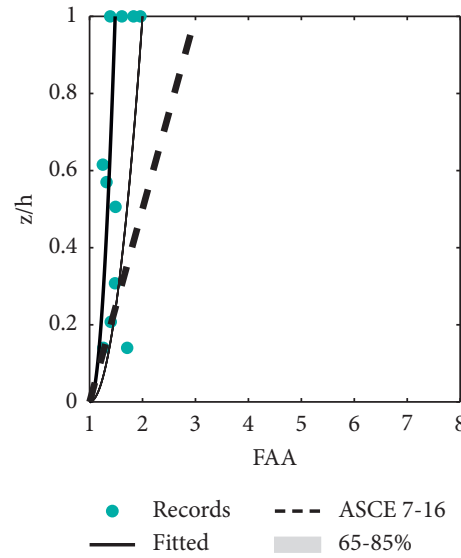

(h)

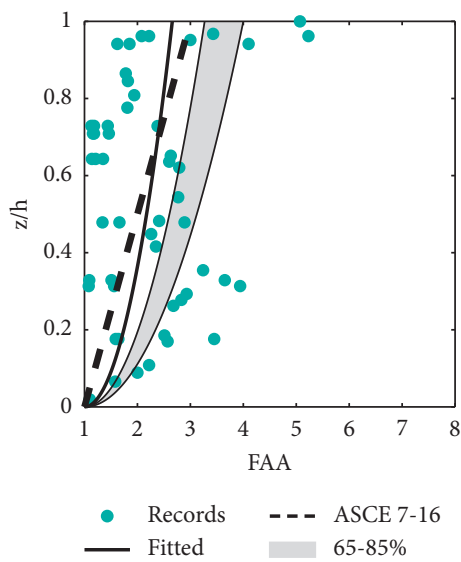

(i)

FIGURE 3: FAA in the concrete buildings: (a) lowrise (PGA <0.035 g); (b) lowrise (0.035 g-0.1 g); (c) lowrise (0.1 g-0.2 g); (d) lowrise ( $>0.2 \mathrm{~g})$; (e) highrise (<0.035 g); (f) highrise $(0.035 \mathrm{~g}-0.1 \mathrm{~g})$; (g) highrise $(0.1 \mathrm{~g}-0.2 \mathrm{~g})$; (h) highrise $(>0.2 \mathrm{~g})$; (i) skyscraper $(<0.035 \mathrm{~g})$.

the FAA profile was underestimated because many records ran outside of the profile. This trend was quite similar to that in the concrete and steel buildings. At the PGA between 0.1 and $0.2 \mathrm{~g}$ (Figure 5(c)), the FAA merely enveloped one record among the five, which showed the worst estimation among the three types of profiles. A more reliable profile could be developed if more records were given. In the three earthquake levels, the fitting and $65 \%$ of the envelopment profiles were identical. For the velocity factor, there was no apparent trend to be summarized. The magnitude was reduced from frequent for the basic earthquake levels, but it increased again at the rare earthquake level (Table 6). The percentage-based profile looked more reliable than the other two profiles did. 
TABLE 4: Velocity factor $(\alpha)$ in the concrete buildings.

\begin{tabular}{|c|c|c|c|c|c|}
\hline Height type & PGA (g) & Fitted & $65 \%$ & $75 \%$ & $85 \%$ \\
\hline \multirow{4}{*}{ Lowrise } & $\leq 0.035$ & 2.25 & 2.34 & 2.74 & 3.00 \\
\hline & $0.035-0.1$ & 2.03 & 1.88 & 2.48 & 3.00 \\
\hline & $0.1-0.2$ & 1.70 & 1.35 & 2.23 & 2.58 \\
\hline & $>0.2$ & 1.31 & 1.53 & 1.82 & 2.02 \\
\hline \multirow{4}{*}{ Highrise } & $\leq 0.035$ & 1.92 & 1.82 & 2.30 & 3.00 \\
\hline & $0.035-0.1$ & 1.82 & 2.15 & 2.66 & 3.00 \\
\hline & $0.1-0.2$ & 0.74 & 1.00 & 1.15 & 1.77 \\
\hline & $>0.2$ & 0.48 & 1.00 & 1.00 & 1.00 \\
\hline \multirow{4}{*}{ Skyscraper } & $\leq 0.035$ & 1.66 & 2.27 & 3.00 & 3.00 \\
\hline & $0.035-0.1$ & NA & NA & NA & NA \\
\hline & $0.1-0.2$ & NA & NA & NA & NA \\
\hline & $>0.2$ & NA & NA & NA & NA \\
\hline
\end{tabular}

Note. "NA" denotes that no data were available.

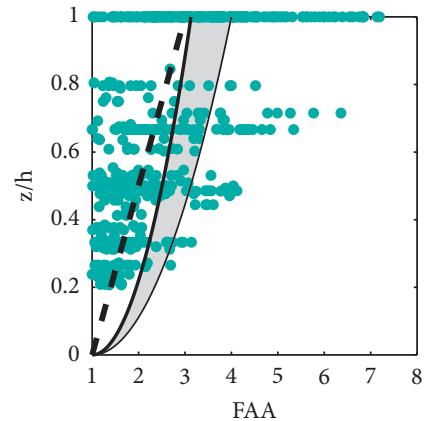

- Records - - - ASCE 7-16

- Fitted $\quad 65-85 \%$

(a)

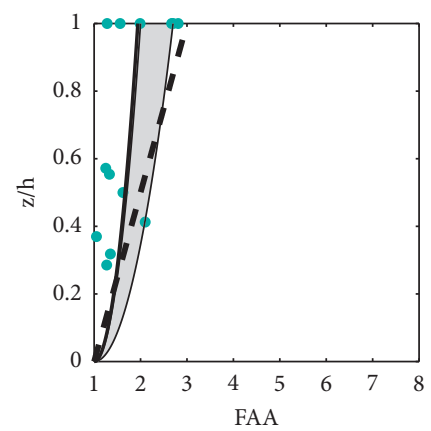

- Records - -- ASCE 7-16

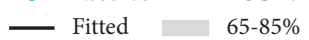

(d)

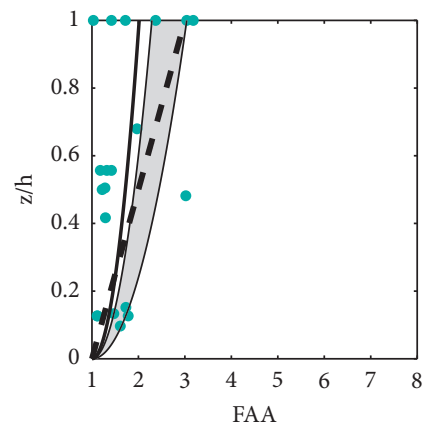

- Records - -- ASCE 7-16 Fitted 65-85\%

(g)

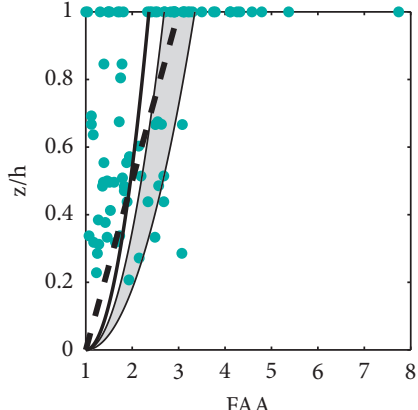

- Records - - - ASCE 7-16

Fitted $\square 5-85 \%$

(b)

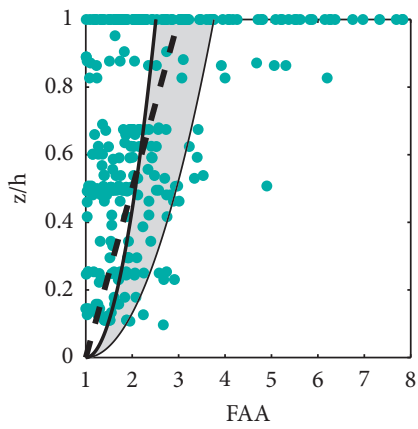

- Records - - - ASCE 7-16

- Fitted $\quad 65-85 \%$

(e)

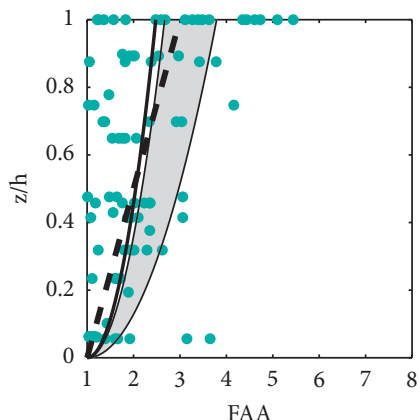

- Records -- - ASCE 7-16

Fitted $\quad 65-85 \%$

(h)

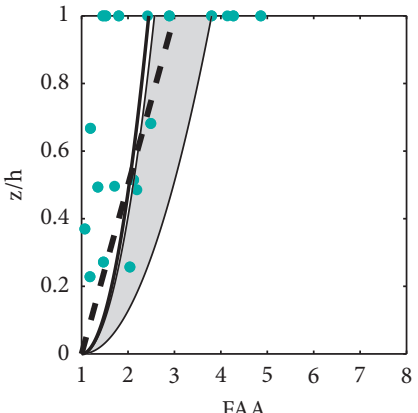

- Records - - - ASCE 7-16

Fitted $65-85 \%$

(c)

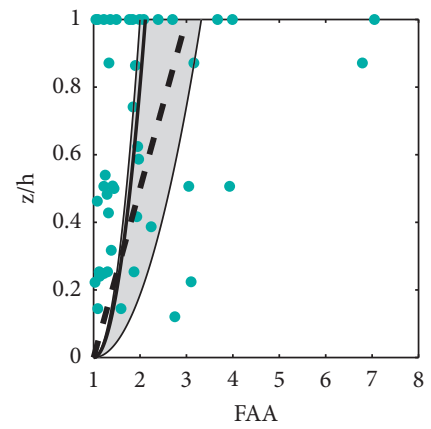

- Records - - - ASCE 7-16

- Fitted 65-85\%

(f)

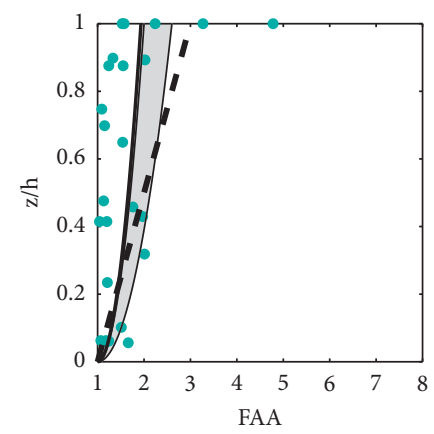

- Records - - - ASCE 7-16

- Fitted 65-85\%

(i)

Figure 4: Continued. 


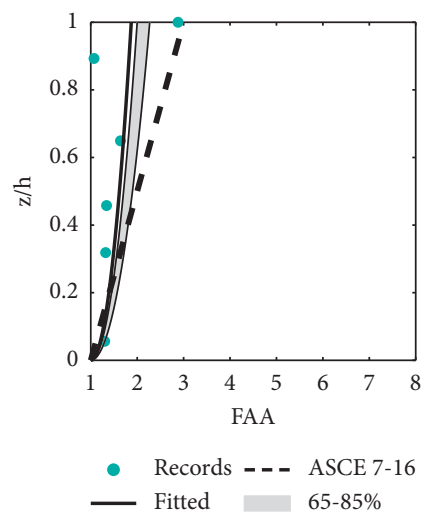

(j)

FIGURE 4: FAA in steel buildings: (a) steel lowrise (PGA <0.035 g); (b) steel lowrise (0.035 g-0.1 g); (c) steel lowrise (0.1 g-0.2 g); (d) steel lowrise (>0.2 g); (e) steel highrise (PGA <0.035 g); (f) steel highrise $(0.035 \mathrm{~g}-0.1 \mathrm{~g})$; (g) steel highrise $(0.1 \mathrm{~g}-0.2 \mathrm{~g})$; (h) steel skyscraper (PGA $<0.035 \mathrm{~g})$; (i) steel skyscraper $(0.035 \mathrm{~g}-0.1 \mathrm{~g})$; (j) steel skyscraper $(0.1-0.2 \mathrm{~g})$.

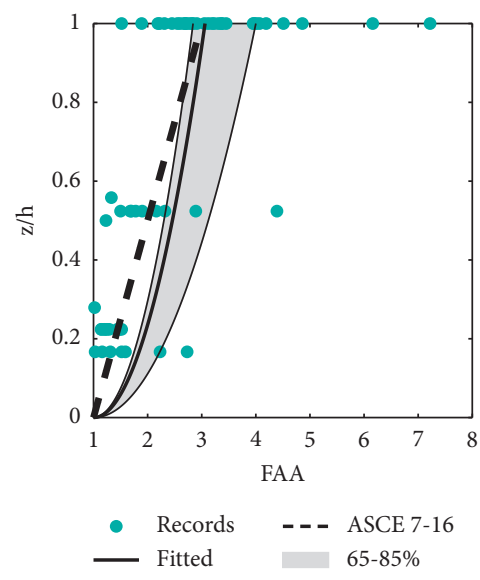

(a)

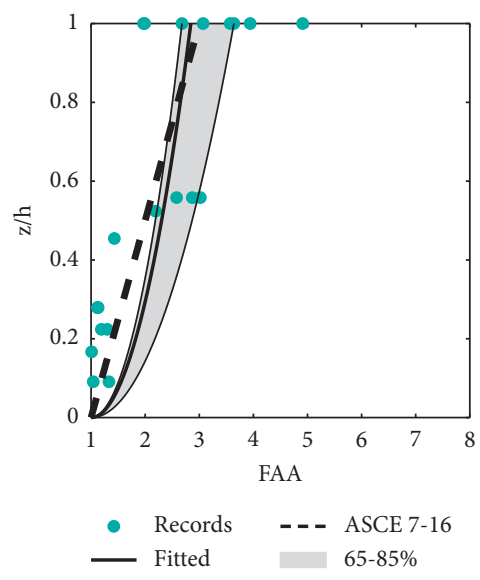

(b)

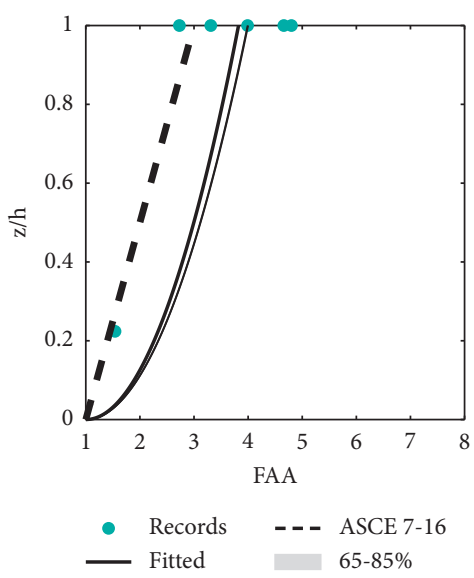

(c)

FIgURe 5: FAA in masonry buildings: (a) PGA <0.035 g; (b) $0.035-0.1 \mathrm{~g}$; (c) $0.1-0.2 \mathrm{~g}$.

TABLE 5: Velocity factor $(\alpha)$ in the steel buildings.

\begin{tabular}{lccccc}
\hline Height type & PGA $(\mathrm{g})$ & Fitted & $65 \%$ & $75 \%$ & $85 \%$ \\
\hline \multirow{4}{*}{ Lowrise } & $\leq 0.035$ & 2.14 & 2.13 & 2.73 & 3.00 \\
& $0.035-0.1$ & 1.36 & 1.69 & 2.03 & 2.35 \\
& $0.1-0.2$ & 1.45 & 1.57 & 1.89 & 2.80 \\
& $>0.2$ & 0.94 & 1.00 & 1.00 & 1.70 \\
\hline \multirow{4}{*}{ Highrise } & $\leq 0.035$ & 1.57 & 1.51 & 2.03 & 2.76 \\
& $0.035-0.1$ & 1.14 & 1.00 & 1.39 & 2.32 \\
& $0.1-0.2$ & 1.02 & 1.29 & 1.88 & 2.04 \\
& $>0.2$ & $\mathrm{NA}$ & $\mathrm{NA}$ & $\mathrm{NA}$ & $\mathrm{NA}$ \\
\hline \multirow{3}{*}{ Skyscraper } & $\leq 0.035$ & 1.48 & 1.67 & 2.21 & 2.79 \\
& $0.1-0.2$ & 0.93 & 1.00 & 1.24 & 1.60 \\
& $>0.2$ & $\mathrm{NA}$ & $\mathrm{NA}$ & $\mathrm{NA}$ & $\mathrm{NA}$ \\
\hline
\end{tabular}

Note. "NA" denotes that no data were available.

4.4. Timber Buildings. Only nine timber buildings were instrumented, most of which were one-story. The tallest one was the four-story residential building in Stanford (CSMIP \#
TABLE 6: Velocity factor $(\alpha)$ in the lowrise masonry buildings.

\begin{tabular}{lcccc}
\hline PGA $(\mathrm{g})$ & Fitted & $65 \%$ & $75 \%$ & $85 \%$ \\
\hline$\leq 0.035$ & 2.06 & 1.84 & 2.31 & 3.00 \\
$0.035-0.1$ & 1.84 & 1.68 & 2.51 & 2.64 \\
$0.1-0.2$ & 2.82 & 2.99 & 3.00 & 3.00 \\
$>0.2$ & NA & NA & NA & NA \\
\hline
\end{tabular}

Note. "NA" denotes that no data were available or that the number of data points was $<5$.

$58,019,12.2 \mathrm{~m}$ ), California, USA. At PGA $<0.035 \mathrm{~g}$, the fitted profile matched the suggested profile in ASCE 7-16 at the roof (Figure 6(a)). Again, similar to the profiles in the concrete, steel, and masonry buildings, fewer records were enveloped in the other stories. When the PGA was between $0.035 \mathrm{~g}$ and $0.1 \mathrm{~g}$, the corresponding FAA given by ASCE716 was larger than the other two profiles at the roof (Figure 6(b)). The velocity factors in the two earthquake levels were obtained (Table 7). The corresponding values at PGA $<0.035 \mathrm{~g}$ were larger than that of PGA $>0.035 \mathrm{~g}$. Similar 


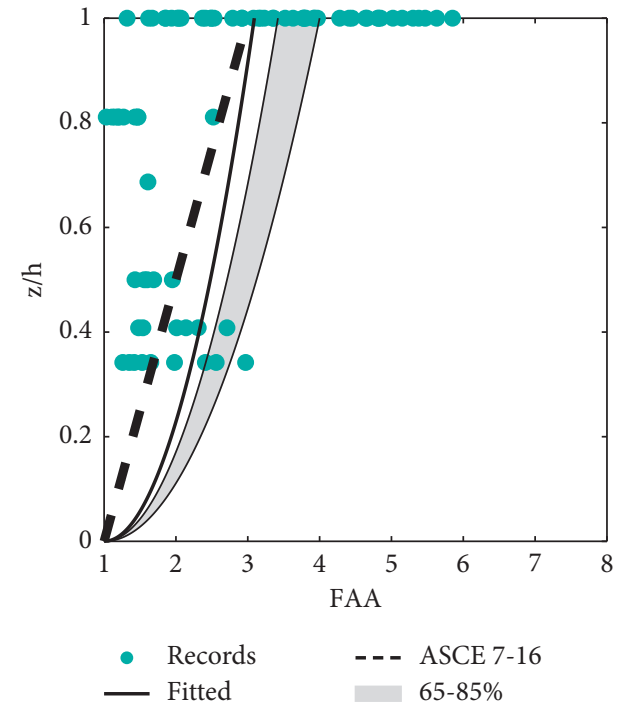

(a)

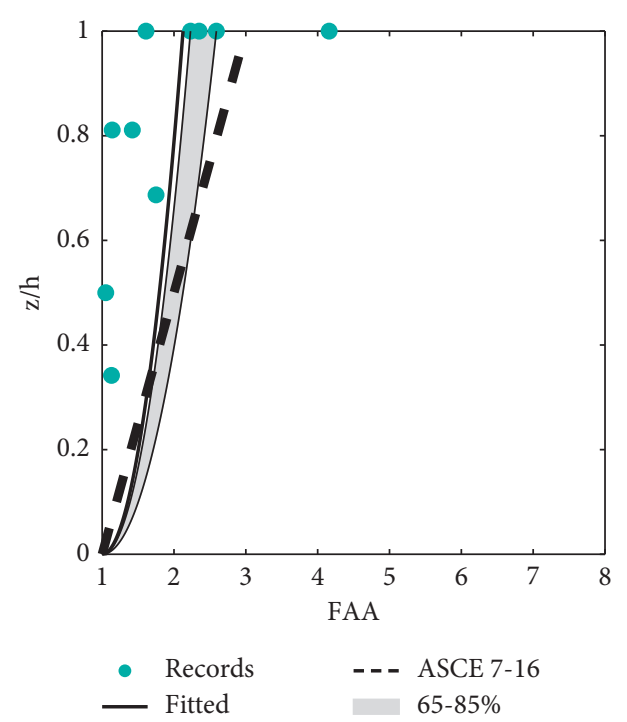

(b)

Figure 6: FAA in the lowrise timber buildings: (a) PGA <0.035 g; (b) 0.035-0.1 g.

TABLE 7: Velocity factor $(\alpha)$ in the lowrise timber buildings.

\begin{tabular}{lcccc}
\hline PGA $(\mathrm{g})$ & Fitted & $65 \%$ & $75 \%$ & $85 \%$ \\
\hline$\leq 0.035$ & 2.09 & 2.42 & 2.81 & 3.00 \\
$0.035-0.1$ & 1.13 & 1.23 & 1.35 & 1.59 \\
$0.1-0.2$ & NA & NA & NA & NA \\
$>0.2$ & NA & NA & NA & NA \\
\hline
\end{tabular}

Note. "NA" denotes that no data were available or that the number of data points was $<5$.

to the scenario in the masonry buildings, more records were needed to acquire a representative distribution profile of the FAA.

\section{Discussion}

\subsection{Roof Acceleration Amplification (RAA)}

5.1.1. Percentage of Exceedance. Generally, the acceleration amplification factor, FAA, achieved the peak value for the roof of the instrumented buildings. In the computation of the equivalent seismic force of the NCs, this factor, namely, the roof acceleration amplification (RAA), was taken conservatively. However, most of the instrumented RAAs were larger than the 3.00 provided in ASCE 7-16 [6]. The percentage of exceedance (POE) of 3.00 is shown in Figure 7. In the concrete buildings (Figure 7(a)), the magnitude of the POE decreased with the increasing PGA as a result of the consequent increasing nonlinearity of the buildings $[27,32,33,56,60,65]$. For the same earthquake excitation level, the POE of the lowrise buildings (65\%) was larger than that of the highrises (55\%). In the lowrise and highrise steel buildings (Figure $7(\mathrm{~b})$ ), however, the POEs of PGA $<0.035 \mathrm{~g}$ were slightly smaller than those of the PGA between $0.1 \mathrm{~g}$ and $0.2 \mathrm{~g}$. The numbers of records of the skyscrapers were 5 and 19 for the concrete and steel buildings, respectively. The corresponding POEs may not have represented the general properties of these two types of buildings. All the masonry and timber buildings were lowrises (Figures $7(\mathrm{c})$ and $7(\mathrm{~d})$ ). There was no clear trend for the POE in these buildings. With the frequent and basic earthquake excitations, the largest POEs were $80 \%$ and $64 \%$, which was considerable for the NCs attached in these buildings. There were no skyscrapers or highrises for the masonry or timber buildings that were instrumented, so it was difficult to address a comment on the code specification.

5.1.2. Percentile Distribution. The percentile distributions (empirical cumulative distribution function with exchanged coordinates) of the RAA in the instrumented buildings are shown in Figure 8. The RAA was larger than 3.00 at the $42^{\text {nd }}$ percentile in the lowrise concrete buildings for the PGA smaller than $0.2 \mathrm{~g}$ (Figure $8(\mathrm{a})$ ). For the PGA $>0.2 \mathrm{~g}$, the resulting RAA was smaller than 3.00 until the $73^{\text {rd }}$ percentile. Given the same percentile, the RAA was reduced with the decreasing magnitude of the PGA. The corresponding percentile had the same trend in the highrise concrete buildings (Figure 8(b)), but the highest value of the RAA was smaller than 3.00 at all percentiles at PGA $>0.1 \mathrm{~g}$. The trend in the steel buildings was different from that in the concrete buildings (Figures $8(\mathrm{c})$ and $8(\mathrm{~d})$ ). When the PGA was between 0.1 and $0.2 \mathrm{~g}$, the resulting magnitude of the RAA was larger than that between 0.035 and $0.1 \mathrm{~g}$ for the whole percentiles. In the lowrise masonry buildings, the RAA for the PGA $<0.035 \mathrm{~g}$ was the largest at the $1^{\text {st }}$ to $80^{\text {th }}$ percentiles (Figure $8(\mathrm{e})$ ). Only two earthquake levels were recorded in the lowrise timber buildings (Figure 8(f)). The resulting RAA was larger than 3.00 at a percentile larger than $35^{\text {th }}$. In summary, a considerable amount of the recorded RAAs were larger than the code provisions [6], namely, 3.00. The observation agreed with the percentage of exceedance shown in Figure 7. The percentile distribution of the RAA of the skyscraper buildings was not elaborated because the related 


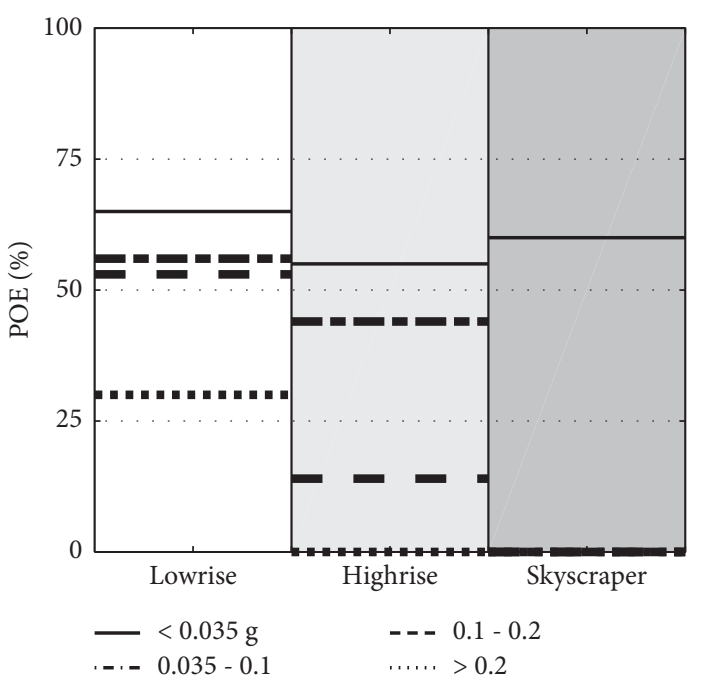

(a)

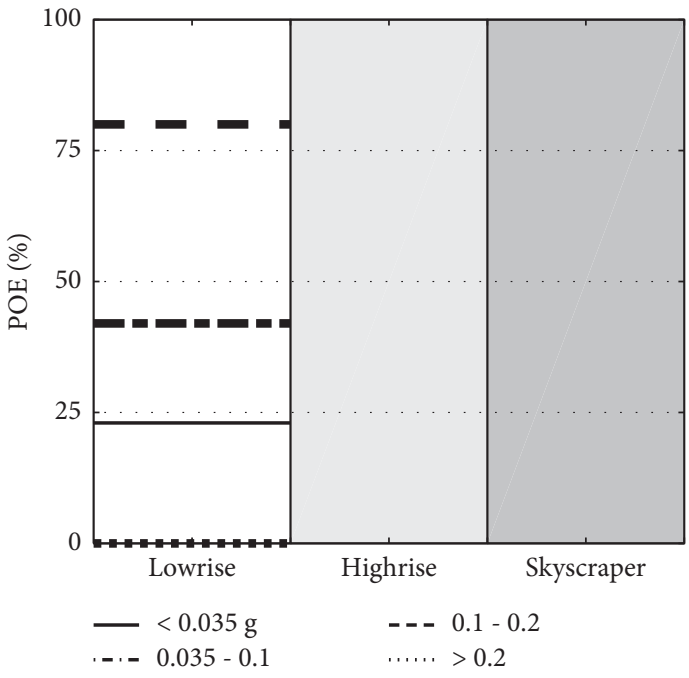

(c)

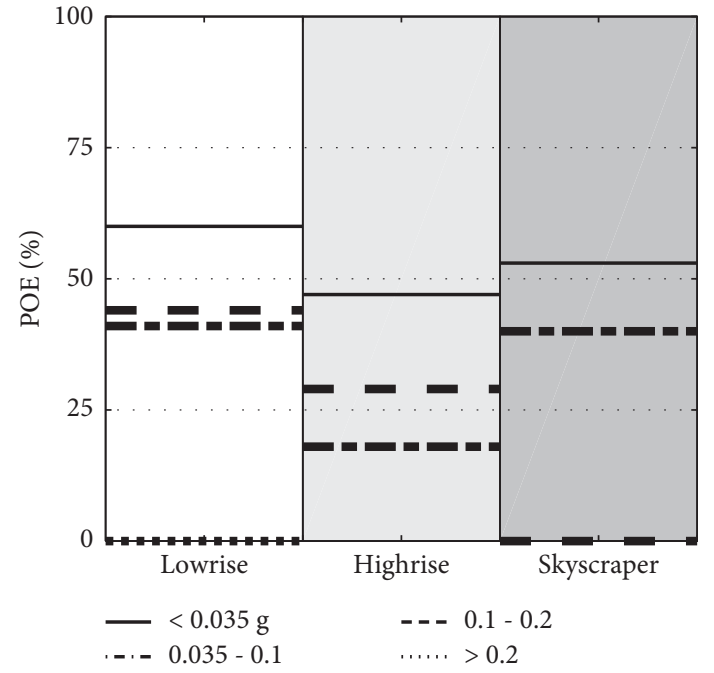

(b)

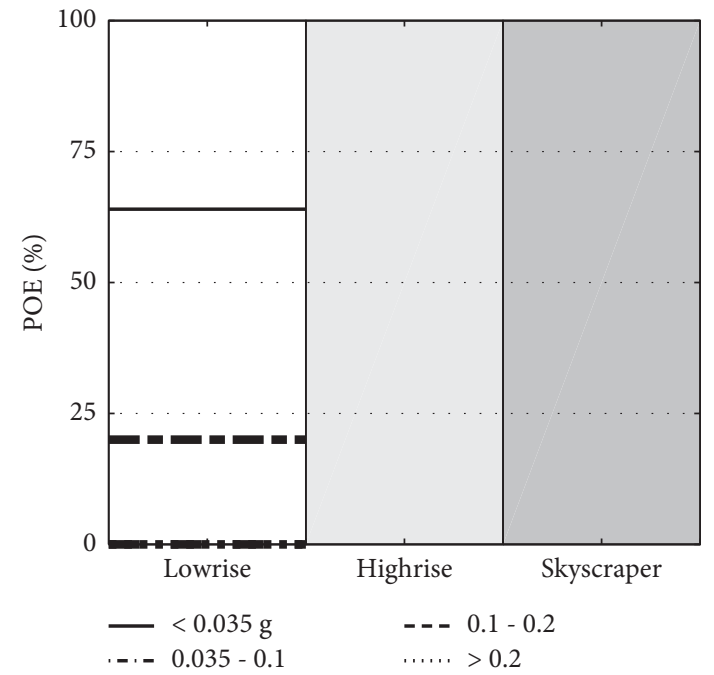

(d)

Figure 7: Percentage exceeding 3.00: (a) concrete; (b) steel; (c) masonry; (d) timber.

records were limited. The results of the $65^{\text {th }}, 75^{\text {th }}$, and $85^{\text {th }}$ percentiles of all the buildings are listed in Table 8 . The magnitudes of the RAAs in the table were different from those obtained in [38] because different data processing methods were applied. The given RAA for the skyscrapers was not reliable because of the limited amount of records. These data were beneficial for determining the proper value of the RAA and then computing the seismic design force of the NC mountings in the building structures.

It was noted that the percentile RAA values were different from those obtained from the nonlinear least square curve fitting (Section 4). The reason for this was that the percentile analysis used the records in the roof of the instrumented buildings only, and the magnitude of the data was usually the largest in each record. The other method employed all of the data for the roof or the other stories for which the corresponding FAAs were typically smaller than those in the roof. Accordingly, the resulting RAA was smaller than that obtained from the percentile analysis. This is a normal issue for fitted versus actual RAA records.

5.1.3. Recorded FAAs beyond CSMIP. In the great 921 ChiChi earthquake (Taiwan, Sep. 21, 1999), in addition to the extensive casualties and failure of the building structures, damage to the NCs appeared in critical facilities such as schools and hospitals [66]. The roof accelerations of the instrumented buildings were recorded. The resulting RAAs are listed in Table 9. According to the height and the PGA of these buildings, the largest RAAs that were obtained were $5.00 \quad(\mathrm{PGA}=0.037 \mathrm{~g}), \quad 4.35 \quad(\mathrm{PGA}=0.034 \mathrm{~g}), \quad$ and 3.57 $(\mathrm{PGA}=0.022 \mathrm{~g})$ for the lowrise, highrise, and skyscraper buildings, respectively. For the telecommunication building in Tainan, the $85^{\text {th }}$ percentile RAA was 4.56 , as shown in Table 8, which was smaller than 5.00. For the office building in Taoyen, the recorded FAA (3.77) was larger than that of 


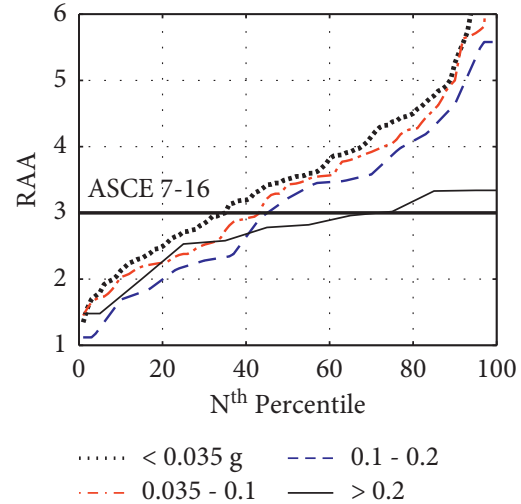

(a)

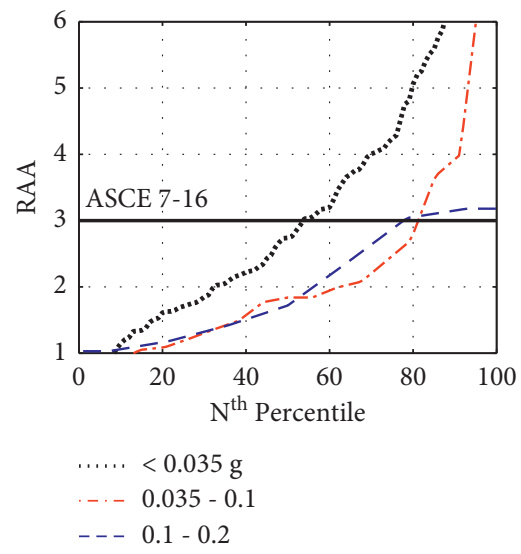

(d)

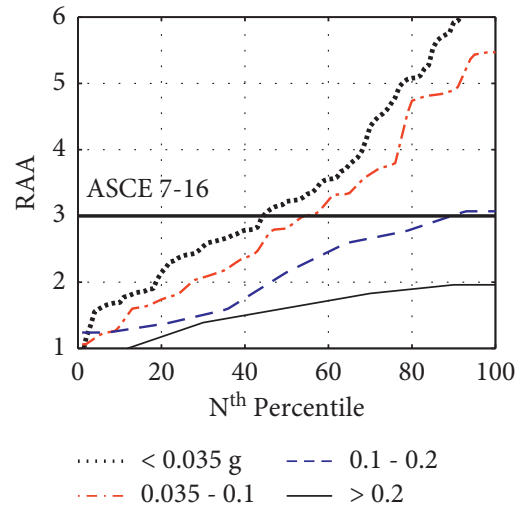

(b)

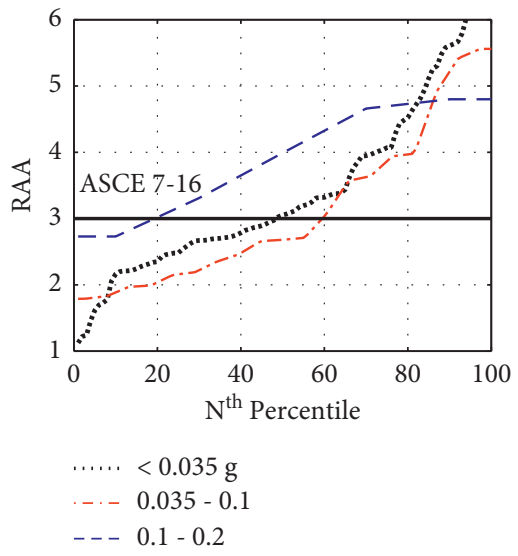

(e)

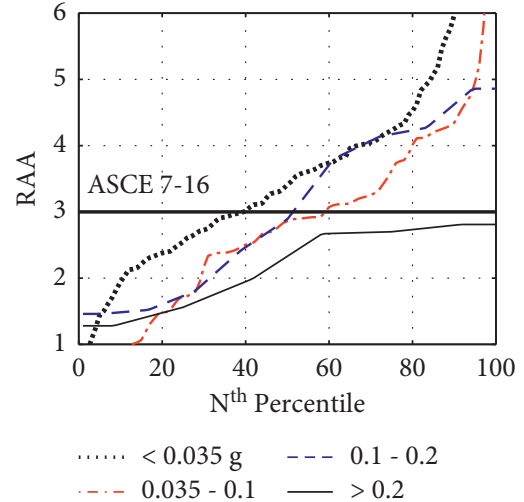

(c)

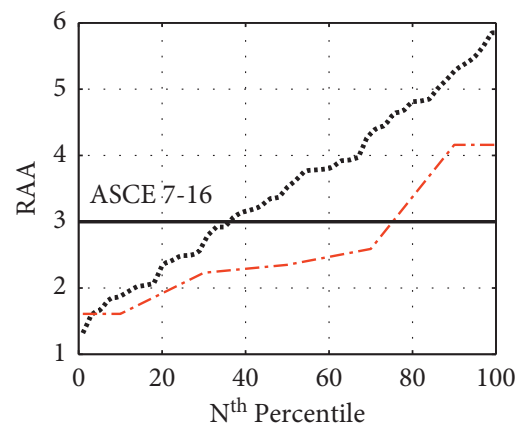

$\cdots \cdots<0.035 \mathrm{~g}$

-.- $0.035-0.1$

(f)

Figure 8: Percentile distribution of the roof acceleration amplification: (a) lowrise concrete; (b) highrise concrete; (c) lowrise steel; (d) highrise steel; (e) lowrise masonry; (f) lowrise timber.

TABLE 8: Roof acceleration amplification $(\mathrm{RAA})$ at the $65^{\text {th }}, 75^{\text {th }}$, and $85^{\text {th }}$ percentiles.

\begin{tabular}{lccccccccccccc}
\hline \multirow{2}{*}{ Building type } & \multirow{2}{*}{ Height level } & \multicolumn{3}{c}{ PGA $\leq 0.035 \mathrm{~g}$} & \multicolumn{3}{c}{ PGA } & $0.035-0.1$ & \multicolumn{3}{c}{ PGA $0.1-0.2$} & \multicolumn{3}{c}{ PGA >0.2 } \\
& & $65^{\text {th }}$ & $75^{\text {th }}$ & $85^{\text {th }}$ & $65^{\text {th }}$ & $75^{\text {th }}$ & $85^{\text {th }}$ & $65^{\text {th }}$ & $75^{\text {th }}$ & $85^{\text {th }}$ & $65^{\text {th }}$ & $75^{\text {th }}$ & $85^{\text {th }}$ \\
\hline \multirow{3}{*}{ Concrete } & Lowrise & 3.92 & 4.38 & 4.77 & 3.80 & 4.05 & 4.56 & 3.51 & 3.87 & 4.31 & 2.96 & 3.02 & 3.35 \\
& Highrise & 3.77 & 4.69 & 5.53 & 3.34 & 3.77 & 4.82 & 2.60 & 2.73 & 2.91 & 1.78 & 1.86 & 1.93 \\
& Skyscraper & 4.69 & 5.11 & 5.19 & NA & NA & NA & NA & NA & NA & NA & NA & NA \\
\hline \multirow{3}{*}{ Steel } & Lowrise & 3.96 & 4.23 & 5.08 & 3.13 & 3.63 & 4.20 & 3.91 & 4.17 & 4.36 & 2.68 & 2.70 & 2.77 \\
& Highrise & 3.70 & 4.23 & 5.58 & 2.04 & 2.47 & 3.62 & 2.40 & 2.87 & 3.10 & NA & NA & NA \\
& Skyscraper & 3.61 & 4.41 & 4.69 & 3.01 & 3.64 & 4.40 & NA & NA & NA & NA & NA & NA \\
\hline Masonry & Lowrise & 3.44 & 4.07 & 5.12 & 3.50 & 3.87 & 4.58 & 4.49 & 4.70 & 4.77 & NA & NA & NA \\
\hline Timber & Lowrise & 3.93 & 4.59 & 4.93 & 2.53 & 2.98 & 3.77 & NA & NA & NA & NA & NA & NA \\
\hline
\end{tabular}

Note. "NA" denotes that no data were available or that the number of data points was $<4$.

the $65^{\text {th }}$ percentile, while it was smaller than that of the $75^{\text {th }}$ and $85^{\text {th }}$ percentiles $(4.69,5.53)$. For the skyscraper office building in Taipei, the recorded FAA (3.57) was smaller than that of the $65^{\text {th }}$ percentile (4.69).

The corresponding PGAs were small in magnitude because these buildings were located at a distance $>70 \mathrm{~km}$ from the epicenter $(0.015 \mathrm{~g}<\mathrm{PGA}<0.07 \mathrm{~g})$. Under these earthquake excitations, the seismic safety of the NCs in these building was promising because the resulting inertia force was smaller than the one calculated with the code provisions (e.g., ASCE 7-16 [6]) that employed a larger expected design PGA.

In the 2011 Great East Japan earthquake (Mar. 11, 2011), the floor accelerations in two instrumented steel momentframe buildings were recorded $[68,69]$. One was the Shinjuku Campus building of Kogakuin University with 29 stories and a height of $143 \mathrm{~m}$, and the other was the Shinjuku Techno Campus (STEC) office building with 28 stories and a height of $128 \mathrm{~m}$. In both buildings, the earthquake damage to the NCs such as the bookshelves and ceilings appeared in 
TABle 9: RAA in the 1999 Chi-Chi, Taiwan earthquake [67].

\begin{tabular}{|c|c|c|c|c|c|c|c|}
\hline Location & Construction year & Function & Lateral load resisting system & Number of stories & Height $(\mathrm{m})$ & PGA (g) & RAA \\
\hline Jiaoli & 1983 & Hospital & RC frame and shear wall & 6 & 24.2 & 0.022 & 2.16 \\
\hline Hsin-Yen & 1984 & Hospital & $\mathrm{RC}$ frame & 6 & 23.0 & 0.048 & 3.29 \\
\hline Zhongli & 1994 & Library & $\mathrm{RC}$ frame & 8 & 32.2 & 0.044 & 2.90 \\
\hline Hsinchu & 1996 & Library & $\mathrm{RC}$ frame & 8 & 30.4 & 0.029 & 4.21 \\
\hline Tainan & 1989 & Office & $\mathrm{RC}$ frame and shear wall & 8 & 30.4 & 0.036 & 3.56 \\
\hline Tainan & 1980 & Telecom & $\mathrm{RC}$ frame and shear wall & 4 & 20.0 & 0.037 & 5.00 \\
\hline Hsinchu & 1991 & Residential & $\mathrm{RC}$ frame & 14 & 42.6 & 0.055 & 2.99 \\
\hline Miaoli & 1992 & Residential & RC frame & 17 & 56.1 & 0.055 & 2.34 \\
\hline Taoyen & 1994 & Office & Steel beams and concrete columns & 17 & 62.9 & 0.034 & 4.35 \\
\hline Tainan & 1995 & Residential & RC frame and shear wall & 24 & 75.0 & 0.013 & 3.70 \\
\hline Taipei & 1993 & Office & Steel beams and concrete columns & 57 & 205.3 & 0.022 & 3.57 \\
\hline
\end{tabular}

floors higher than the fourteenth stories. The PGAs were between $0.035 \mathrm{~g}$ and $0.1 \mathrm{~g}$. The FAAs of the two buildings are shown in Figure 9. The distribution profiles in ASCE 7-16 [6] and the $85^{\text {th }}$ percentile envelopment of the steel skyscraper ( $\alpha=1.60$ in Table 5 ) could only envelop the FAA in the $22^{\text {nd }}$ and $25^{\text {th }}$ stories. The New Zealand standard [55] provided a relatively good estimation. The RAAs were 3.77 and 3.34 in the two buildings, which were larger than the RAA of the $65^{\text {th }}$ percentile (3.01) but smaller than those of the $75^{\text {th }}$ and $85^{\text {th }}$ percentiles (3.64 and 4.40 in Table 8 ). The reason for this was that the available data for the skyscraper buildings in the CSMIP database were limited. The analytical results could not represent the floor response character of complex buildings such as these two buildings. Therefore, for the tall and special buildings, to obtain a reliable FAA profile for the seismic design of the NCs, the specific floor response of the entire building structures had to be investigated experimentally and/or analytically. This property has been demonstrated in megatall buildings (Shanghai Tower) [56]. As a result, the FAA near the roof level $(z / h \geq 0.90)$ was suggested for specific analysis.

The Engineering Building of Tohoku University (Japan) has experienced two major earthquakes, namely, the June 12, 1978, Miyagi-ken-oki earthquake [69] and the March 11, 2011, earthquake [71]. It is a nine-story reinforced concrete frame building with a height of $32.9 \mathrm{~m}$, so it belonged to the lowrise building category according to Table 1 . The PGAs were $0.24 \mathrm{~g}$ and $0.33 \mathrm{~g}$ for the two main shocks. The resulting RAAs were 4.17 and 2.72 . The former was larger than the $85^{\text {th }}$ percentile (3.35), and the latter was smaller than the $65^{\text {th }}$ percentile (2.96) of the RAA shown in Table 8 . Both values were larger than the corresponding value of the $\mathrm{POE}=85 \%$ (2.02 in Table 4). Neither the statistical results nor the recommended profiles in the code provisions (Figure 9) could address a reasonable estimation of a proper FAA for this building. The FAA records for the strong motion excitation had to be enriched to have a proper prediction.

5.1.4. Application Method. In most code provisions for the seismic design of the NCs, the heightwise linear FAA distribution profiles have been provided (Figure 9). However, the FAA at the roof level, namely, the RAA, is usually applied to computing the equivalent seismic force.

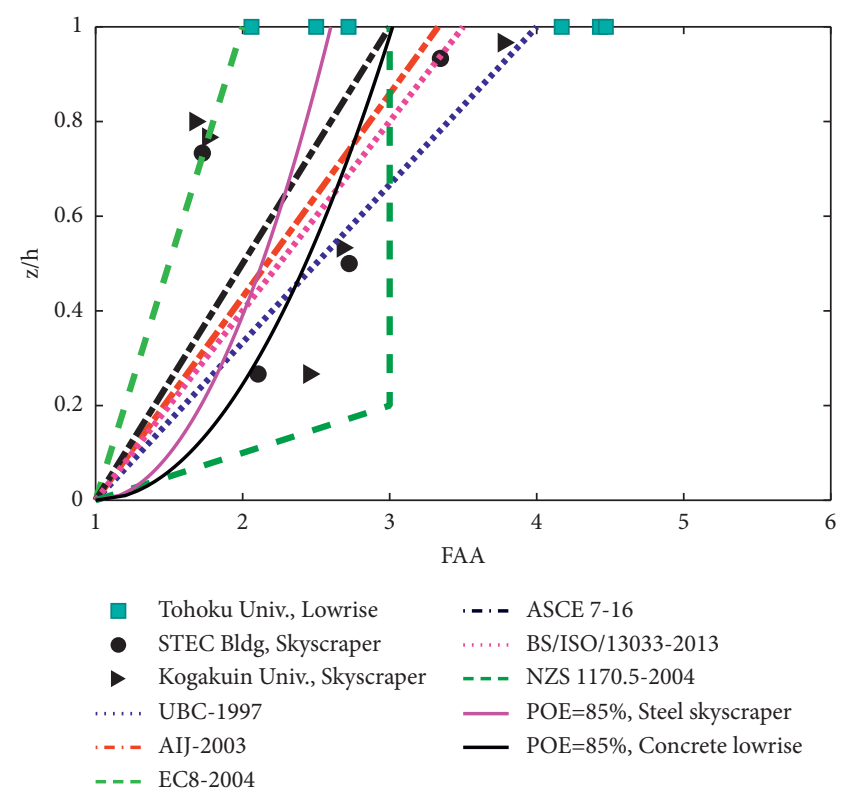

FIGURE 9: FAA in the STEC and Kogakuin University buildings (after [56]).

Some floor-mounted NCs, such as glass curtain walls and ceilings, are light, and the resulting seismic force is smaller than their load-bearing capacity even when using the peak FAA at the roof level $[43,44]$. As a result of insufficient seismic design and fixing measures, the field investigation of the earthquake damage to the various NCs showed that the seismic performance could not be ensured even when using the peak FAA suggested in the codes, e.g., ASCE 716 [72-75]. However, the NCs such as the electrical equipment, pipeline, and switchgear were standard products manufactured by different factories. Unlike the building structures, there were actually limited specific seismic design guidelines to enhance the seismic safety for these products to apply to the seismic prone areas, whether they were installed in the roof or the ground level of the building $[36,75]$. Therefore, the use of the RAA was a reasonable option for the NCs without reliable seismic qualification tests or analysis in the seismic design process. This was especially true for the lowrise and highrise buildings with regular structural configurations. 
In the tall and special buildings where the FAA distribution profiles were unusual and the value of the FAA in the top stories was much larger than the value in the lower stories $[16,17,43,56]$, it was too conservative if the RAA was taken as the representative FAA to compute the seismic force of the NCs. To reduce the budget, multiple values from the FAA distribution profile were allowed to be used in the seismic design of the NCs in these buildings.

5.2. Influence of the Fundamental Period. The approximate periods of the instrumented buildings in the CSMIP database were computed with equation (12) specified in ASCE 7-16 [6]. The period ranges of these buildings are listed in Table 10. To compare the analytical results, the PGA ranges from 0.067 to $0.20 \mathrm{~g}$ and the period ranges from 0.5 to $1.5 \mathrm{~s}$ described in [60] were considered. The PGA was between 0.1 and $0.2 \mathrm{~g}$ in this study. The period range corresponded to the lowrise concrete and steel buildings as well as the highrise masonry buildings. Unfortunately, there were no data on the highrise masonry buildings. Therefore, only concrete and steel buildings were considered. The velocity factors were fitted as shown in Tables 3 and 4. In Figure 10(a), one can find that the FAA profile suggested by [60] was close to that of the lowrise steel buildings but slightly smaller than that of the concrete buildings. For the highrise buildings, however, the authors in [60] apparently overestimated the FAA when compared with this study (Figure 10(b)). It was noted that the disagreement of the FAA distribution profile was due to the different classifications of the PGAs and the building height, which generated a different subset of the records that determined the regressed profiles.

The computed period with equation (12) was an empirical estimation based on the records of limited buildings and earthquake events [77-79]. Analytical studies have proven that a higher mode would cause an effect for the FAA profiles $[27,32]$. Therefore, to understand the actual effect of the building period on the FAA distribution profile, the vibration periods had to be obtained through reliable experimental or analytical approaches. As indicated in equation (11) [37], the RAA was correlated with the fundamental vibration period of the main building. To define this relationship, a subset of 113 recorded floor motions from the 47 instrumented buildings was analyzed [37]. Eight major earthquake events were considered in total. The dataset was classified into two building groups, namely, concrete and steel buildings. The RAAs of these two types are computed and plotted as shown in Figure 11, along with the fundamental vibration period. In general, it was difficult to find a representative trend between them. A parabolic distribution profile was assumed to regress the records with Matlab [64]. The magnitude of the RAA $=1.0$ at period $=0.0 \mathrm{sec}$ when the building is very stiff so that the PGA does not amplify at the roof. However, when the building is very flexible, the resulting RAA will converge to zero so that the PGA is not transferred to the roof. Accordingly, a parabola increases from $(0.0,1.0)$ and then decreases to zero with a high period range, which was reasonable as follows:
TABLE 10: Fundamental period range.

\begin{tabular}{lcccc}
\hline Height type & $\begin{array}{c}\text { Height range } \\
(\mathrm{m})\end{array}$ & \multicolumn{3}{c}{ Period (sec) } \\
& $\leq 35$ & $\leq 1.14$ & $\leq 1.24$ & $\leq 0.70$ \\
Lowrise & $35-100$ & $1.14-2.94$ & $1.24-2.88$ & $0.70-1.54$ \\
Highrise & $100-300$ & $2.94-7.90$ & $2.88-6.94$ & $1.54-3.52$ \\
Skyscraper & $300-600$ & $7.90-14.75$ & $6.94-12.09$ & $3.52-5.92$ \\
Supertall & $>600$ & $>14.75$ & $>12.09$ & $>5.92$ \\
Megatall & & & & \\
\hline
\end{tabular}

$$
R A A=a \cdot T_{1}^{2}+b \cdot T_{1}+1,
$$

where $a$ and $b$ are the coefficients of interest to be determined. The RAA data were fitted using the nonlinear square method (Figure 11). The two computed coefficients for the concrete and steel buildings were $-3.12,5.03$ and $-2.23,4.52$. In addition to the vibration period of the building, other parameters such as the damping ratio and the period components of the ground motion affected the RAA and the FAA. Further investigation should be carried out to define these relations mathematically.

5.3. FAA for Code Implementation. The Pacific Earthquake Engineering Research (PEER) Center developed the performance-based earthquake engineering (PBEE) methodology [80, 81], which has been accepted, and it is widely applied in the community of earthquake engineering $[44,45,82]$. To carry out the PBEE analysis of the NCs, a tentative framework for the nonstructural performance objectives was developed in ATC-120 [37] comprising the hazard definition, damage risk, and performance description. In addition, owner-enhanced performance was suggested to ensure the seismic performance of the NCs with respect to the economic affordability. Accordingly, the three percentages of the FAA distribution profiles (Figures 3-6) could be treated as three performance levels for which the $65 \%$ of envelopment was the basic level, while those for $75 \%$ and $85 \%$ were the enhanced levels determined by the owners. As demonstrated in Figures 3-6, the fitted profiles could actually be represented by those of the $65 \%$ of envelopments. This proved the rationality of using the envelopments of the three percentages.

In the code provisions, it is cumbersome to provide the obtained velocity factors for every type of building, as shown in Tables 4-7. These factors had to be combined and simplified appropriately for the convenience of code implementation. ATC-120 [37] recommended that the seismic design of the NCs should use one representative earthquake level, namely, the design earthquake. This was $2 / 3$ of the maximum considered earthquake. In the earthquake prone region, nonstructural damage might appear at the design PGA $>0.035 \mathrm{~g}[4,6,61]$. However, the records in the CSMIP databases for PGA $>0.1 \mathrm{~g}$ were limited (Table 2), and the resulting velocity factors could not demonstrate the general trend of the FAA profile under this earthquake level. Therefore, the velocity factor for $0.035 \mathrm{~g} \leq \mathrm{PGA}<0.1 \mathrm{~g}$ is the most reliable. Under this earthquake level, regarding the height of the instrumented 


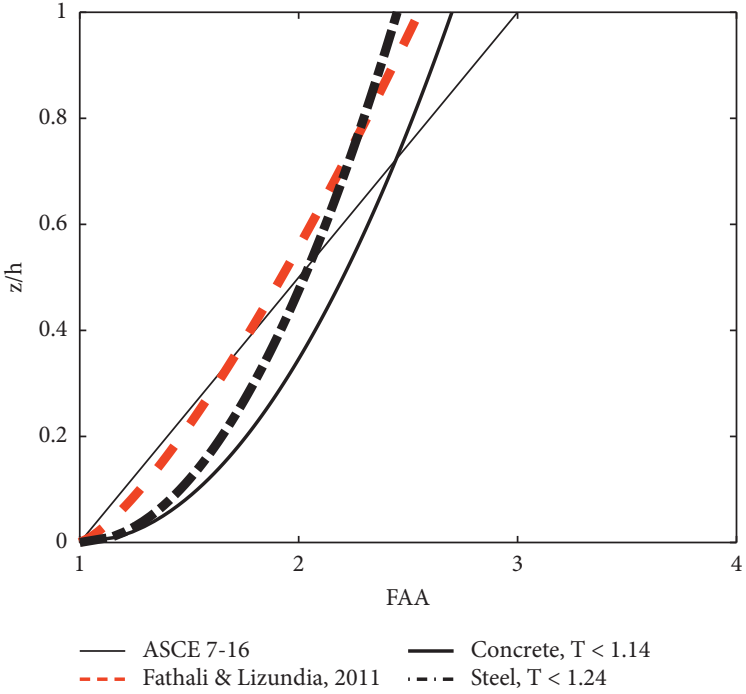

(a)

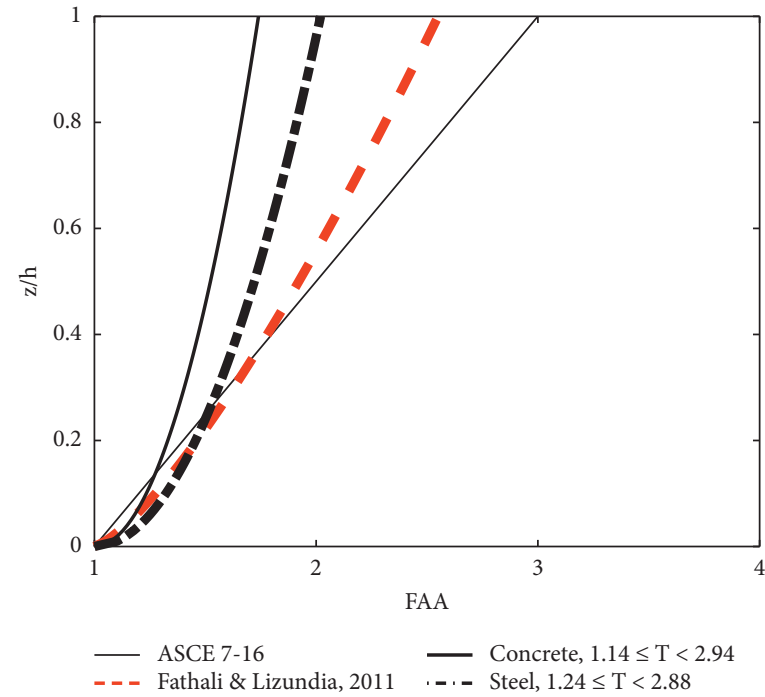

(b)

FIGURE 10: FAA distribution with consideration of the vibration period: (a) lowrise concrete and steel buildings; (b) highrise concrete and steel buildings.

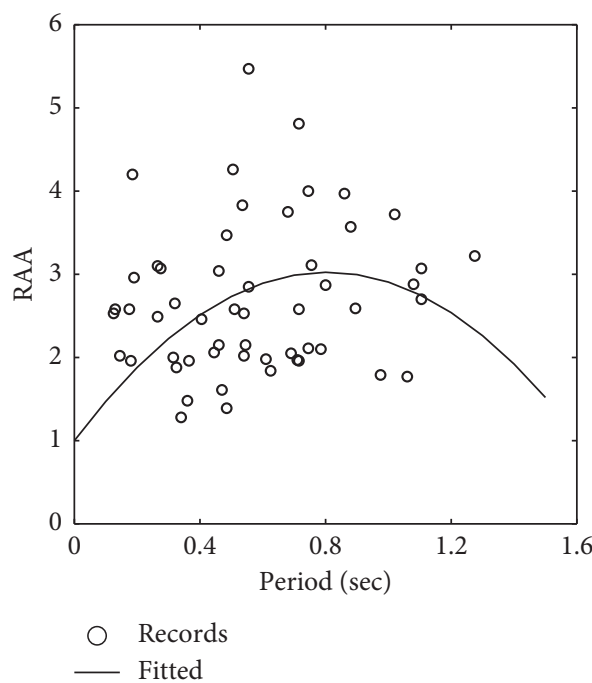

(a)

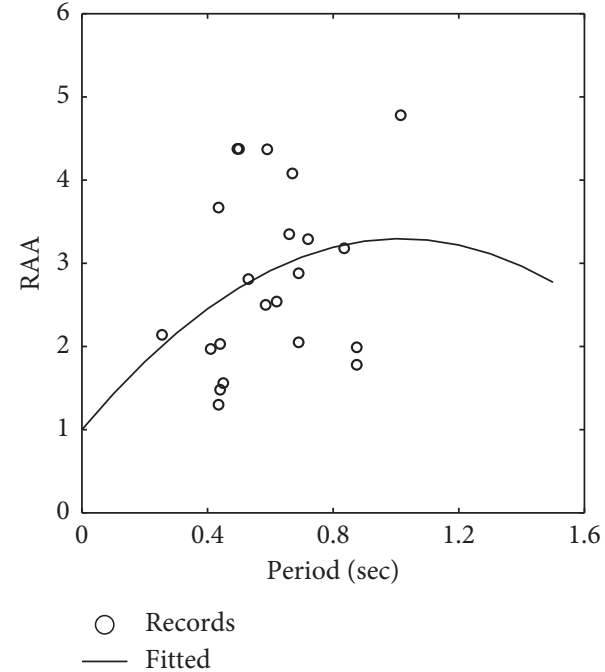

(b)

FIGURE 11: Relationship between vibration period and RAA: (a) concrete buildings; (b) steel buildings.

buildings with the classification shown in Table 1, lowrise buildings accounted for $67 \%$ of the concrete and steel buildings (Table 2). Accordingly, the velocity factor for this lowrise building was the most reliable. All the masonry and timber buildings were lowrise, but there were only five records for the timber buildings, for $0.035 \mathrm{~g} \leq \mathrm{PGA}<0.1 \mathrm{~g}$. Consequently, the velocity factor for timber buildings was not given due to the insufficient records. Considering these scenarios, the suggested reliable velocity factors are shown in Table 11, where the magnitude of the factors was rounded for convenience of application. For the building heights and PGAs beyond this table, the obtained FAA profiles using the velocity factors listed in Tables $4-7$ were not considered reliable enough. 
TABLE 11: Suggested velocity factor $(\alpha)$ for lowrise buildings.

\begin{tabular}{llll}
\hline Building type & $65 \%$ & $75 \%$ & $85 \%$ \\
\hline Concrete & 1.90 & 2.50 & 3.00 \\
Steel & 1.70 & 2.00 & 2.40 \\
Masonry & 1.70 & 2.50 & 2.60 \\
\hline
\end{tabular}

\section{Conclusions}

The seismic performance of NCs has attracted significant attention in the earthquake engineering community. The FAA is one of the important parameters in computing the equivalent seismic force of NCs. In the current study, the FAAs in the instrumented buildings of the CSMIP database were processed with consideration of their structural types, heights, and fundamental vibration periods. Some conclusions are addressed as follows:

(1) The heights of the buildings were classified using a new categorization consisting of five height levels, i.e., lowrise, highrise, skyscraper, supertall, and megatall. The categorization was adapted to the current development of the building structures.

(2) Parabolic distribution profiles were suggested that could envelop most of the FAA data as demonstrated by the processed results. The proposed velocity factor was employed to represent the increment velocity of the parabola. The FAAs that were obtained at the roofs were generally larger than those in other levels were. The percentile distributions of the RAA were computed, and the results showed that the RAA was underestimated in ASCE 7-16 [6]. The PGA-based FAA was suggested for application to the computation of the seismic force of the NCs, instead of the only linear profile ignoring the magnitude of the PGA.

(3) The magnitude of the FAA was influenced by the fundamental vibration period of each building, and this effect was taken into account by classifying the buildings according to period ranges. The relationship between the RAA and the fundamental period of the main building was defined with parabolas for the concrete and steel buildings. In future studies, it is recommended to employ the building period in the FAA equations.

(4) The lowrise buildings had extensive data, so the resulting FAA profiles represented the general dynamic amplification effects in these buildings. A concise version of the FAA profile was suggested for potential code implementation. However, in the highrise and skyscraper buildings, limited data were obtained, and the resulting FAA profile needed further investigation. For the supertall and special buildings, a comprehensive floor acceleration response analysis was needed in order to acquire a reliable FAA distribution.

\section{Data Availability}

The data used to support this study are available upon request to the corresponding author.

\section{Conflicts of Interest}

The authors declare that they have no conflicts of interest.

\section{Acknowledgments}

The presented study was funded by Shanghai Municipal Commission of Housing and Urban-Rural Development with grant \#2021-001-008, Ministry of Science and Technology through grant \#2018YFC0705701, and National Science Foundation of China through grant \#51608381.

\section{References}

[1] A. Shakal, M. J. Huang, and T. Q. Cao, "The whittier narrows, California earthquake of october 1, 1987-CSMIP strong motion data," Earthquake Spectra, vol. 4, no. 1, pp. 75-100, 1988.

[2] E. Miranda, G. Mosqueda, R. Retamales, and G. Pekcan, "Performance of nonstructural components during the 27 February 2010 Chile earthquake," Earthquake Spectra, vol. 28, no. S1, pp. 453-471, 2012.

[3] Y. Chen and T. T. Soong, "Seismic response of secondary systems," Engineering Structures, vol. 10, no. 4, pp. 218-228, 1988.

[4] European Committee for Standardization (ECS), Eurocode 8: Design of Structures for Earthquake Resistance- Part 1: General Rules, Seismic Actions and Rules for Buildings (BS EN 1998-1: 2004), Comite Europeen De Normalisation, Brussels, Belgium, 2005.

[5] Building Seismic Safety Council (BSSC), NEHRP Recommended Provisions for the Development of Seismic Regulations for New Buildings and Structures, National Earthquake Hazards Reduction Program (NEHRP), Washington DC, USA, 2015.

[6] American Society of Civil Engineers (ASCE), Minimum Design Loads for Buildings and Other Structures, SEI/ASCE 716, Reston, VA, USA, 2017.

[7] L. Circelli and D. Chiara, Technical Standards of Construction (NTC 2018), Ministry of Infrastructure and Transport (MIT), Roma, Italy, in Italian, 2018.

[8] T. T. Soong, G. Chen, Z. Wu, R. H. Zhang, and M. Grigoriu, Assessment of the 1991 NEHRP Provisions for Nonstructural Components and Recommended revisions, Report No. NCEER-93-0003, National Center for Earthquake Engineering Research, Buffalo, NY, USA, 1993.

[9] R. Villaverde, "Earthquake Resistant Design of Secondary Structures: A Report on the State of the art," in Proceedings of the 11th World Conference on Earthquake Engineering, Elsevier Science Ltd, Acapulco, Mexico, June 1996.

[10] B. E. Kehoe and S. A. Freeman, A Critique of Procedures for Calculating Seismic Design Forces for Nonstructural elements. Seminar on Seismic Design, Retrofit, and Performance of Nonstructural Components, ATC-29-1, Applied Technology Council, Redwood City, CA, USA, 1998.

[11] G. R. Searer and S. A. Freeman, "Impact of the reliability/ redundancy factor on design," in Proceedings of the 7th U.S. National Conference on Earthquake Engineering, Boston, MA, USA, July 2002.

[12] J. M. Ayres and F. Brown, A Report on Non-structural Damage to Buildings: Alaska Earthquake, Consulting Engineers Association of California, Sacramento, CA, USA, 1971.

[13] H. S. Lew, E. V. Leyendecker, and R. D. Dikkers, Engineering Aspects of the 1971 San Fernando Earthquake, Institute for 
Applied Technology National Bureau of Standards, Washington, DC, USA, 1971.

[14] J. G. Meehan, "California's hospital seismic safety Act," in Proceedings of the 8th World Conference on Earthquake Engineering, San Francisco, CA, USA, July 1986.

[15] D. Ding and C. Arnold, "Architecture, building contents, and building systems," Earthquake Spectra, vol. 6, no. S1, pp. 339-377, 1990 .

[16] M. Çelebi and E. Şafak, "Seismic response of transamerica building. I: data and preliminary analysis," Journal of Structural Engineering, vol. 117, pp. 2389-2404, 1991.

[17] M. Çelebi and E. Şafak, "Seismic response of pacific Park Plaza. I: data and preliminary analysis," Journal of Structural Engineering, vol. 118, pp. 1547-1565, 1992.

[18] A. F. Shakal, M. J. Huang, and R. B. Darragh, "Recorded ground and structure motions," Earthquake Spectra, vol. 11, no. S2, pp. 13-96, 1995.

[19] T. T. Soong, R. E. Bachman, and R. M. Drake, "Implications of the 1994 Northridge earthquake on design guidelines for nonstructural components," in Proceedings of the NEHRP Conference and Workshop on Research on the Northridge California Earthquake of January 17, 1994, pp. 441-448, California Universities for Research in Earthquake Engineering, San Diego, CA, USA, January 1994.

[20] M. E. Rodriguez, J. I. Restrepo, and A. Carr, "Earthquakeinduced floor horizontal accelerations in buildings," Earthquake Engineering \& Structural Dynamics, vol. 31, pp. 693718, 2002.

[21] American Society of Civil Engineers (ASCE), Minimum Design Loads for Buildings and Other Structures, SEI/ASCE 710, Reston, VA, USA, 2011.

[22] S. R. Chaudhuri and T. C. Hutchinson, "Distribution of peak floor acceleration for estimating nonstructural vulnerability," in Proceedings of the 13th World Conference on Earthquake Engineering, Vancouver, B.C. Canada, August 2004.

[23] E. Reinoso and E. Miranda, "Estimation of floor acceleration demands in high-rise buildings during earthquakes," Structural Design of Tall and Special Buildings, vol. 14, pp. 107-130, 2005.

[24] M. P. Singh, L. M. Moreschi, L. E. Suárez, and E. E. Matheu, "Seismic design forces. I: rigid nonstructural components," Journal of Structural Engineering, vol. 132, pp. 1524-1532, 2006.

[25] M. P. Singh, L. M. Moreschi, L. E. Suárez, and E. E. Matheu, "Seismic design forces. II: flexible nonstructural components," Journal of Structural Engineering, vol. 132, pp. 1533-1542, 2006.

[26] R. Villaverde, "Simple method to estimate the seismic nonlinear response of nonstructural components in buildings," Engineering Structures, vol. 28, pp. 1209-1221, 2006.

[27] R. A. Medina, R. Sankaranarayanan, and K. M. Kingston, "Floor response spectra for light components mounted on regular moment-resisting frame structures," Engineering Structures, vol. 28, pp. 1927-1940, 2006.

[28] E. Miranda and S. Taghavi, "A comprehensive study of floor acceleration demands in Multi-story buildings," in Proceedings of the ATC \& SEI Conference on Improving the Seismic Performance of Existing Buildings and Other Structures, pp. 616-626, San Francisco, CA, USA, December 2009.

[29] S. Taghavi and E. Miranda, "Response spectrum method for estimation of peak floor acceleration demand," in Proceedings of the ATC \& SEI Conference on Improving the Seismic Performance of Existing Buildings and Other Structures, pp. 627-638, San Francisco, CA, USA, December 2009.
[30] S. R. Chaudhuri and T. C. Hutchinson, "Effect of nonlinearity of frame buildings on peak horizontal floor acceleration," Journal of Earthquake Engineering, vol. 15, pp. 124-142, 2011.

[31] M. Pozzi and A. D. Kiureghian, "Response spectrum analysis for floor acceleration," Earthquake Engineering \& Structural Dynamics, vol. 44, pp. 2111-2127, 2015.

[32] C. Petrone, G. Magliulo, and G. Manfredi, "Seismic demand on light acceleration-sensitive nonstructural components in European reinforced concrete buildings," Earthquake Engineering \& Structural Dynamics, vol. 44, pp. 1203-1217, 2015.

[33] L. Moschen, C. Adam, and D. Vamvatsikos, "A response spectrum method for peak floor acceleration demands in earthquake excited structures," Probabilistic Engineering Mechanics, vol. 46, pp. 94-106, 2016.

[34] H. Anajafi and R. Medina, "Evaluation of ASCE 7 equations for designing acceleration sensitive nonstructural components using data from instrumented buildings," Earthquake Engineering \& Structural Dynamics, vol. 47, pp. 1075-1094, 2018.

[35] B. Huang, W. Lu, and S. Günay, "Shaking table tests of granite cladding with dowel pin connection," Bulletin of Earthquake Engineering, vol. 18, pp. 1081-1105, 2020.

[36] D. Saldana and V. Terzic, "Simplified analysis response models for SCBF and BRBF compliant with FEMA P-58 simplified procedures," FEMA P-58/BD-3.7.21, Thesis, Applied Technology Council, Redwood City, CA, USA, 2018.

[37] Applied Technology Council (ATC), Recommendations for improved seismic performance of nonstructural components (ATC-120), Report NIST GCR 18-917-43, National Institute of Standards and Technology (NIST), Gaithersburg, MD, USA, 2019.

[38] A. B. El Ezz, R. Assi, and T. Z. Miralvand, "Seismic floor acceleration amplification based on instrumented building records," Journal of Architectural Engineering, vol. 26, Article ID 04020004, 2020.

[39] Applied Technology Council (Atc), Seismic Performance Assessment of Buildings, Prepared for Federal Emergency Management agency, FEMA-P58. ATC, Washington, DC, USA, 2012.

[40] T. Kashima, S. Koyama, M. Iiba, and I. Okawa, "Change in dynamic characteristics of RC/SRC buildings during the 2011 Great East Japan earthquake," in Proceedings of the 10th US National Conference on Earthquake Engineering, Earthquake Engineering Research Institute, Anchorage, AK, USA, July 2014.

[41] A. K. Kazantzi, D. Vamvatsikos, and E. Miranda, "Evaluation of seismic acceleration demands on building nonstructural elements," Journal of Structural Engineering, vol. 146, 2020.

[42] A. K. Kazantzi, D. Vamvatsikos, and E. Miranda, "The effect of damping on floor spectral accelerations as inferred from instrumented buildings," Bulletin of Earthquake Engineering, vol. 18 , pp. 2149-2164, 2020 b.

[43] W. Lu, B. Huang, K. M. Mosalam, and S. Chen, "Experimental evaluation of a glass curtain wall of a tall building," Earthquake Engineering \& Structural Dynamics, vol. 45, pp. 1185$1205,2016$.

[44] B. Huang, X. Hua, W. Lu, and Q. Zhang, "Floor acceleration amplification factor in the instrumented buildings under historical earthquake excitations," China Civil Engineering Journal, vol. 53, pp. 16-27, 2020, in Chinese.

[45] B. Huang, W. Lu, S. Chen, and K. M. Mosalam, "Shaking table testing of the granite cladding with undercut bolt anchorage," Engineering Structures, vol. 171, pp. 488-499, 2018. 
[46] T. Wang, Q. Shang, and J. Li, "Seismic force demands on acceleration-sensitive nonstructural components: a state-ofthe-art review," Earthquake Engineering and Engineering Vibration, vol. 20, pp. 39-62, 2021.

[47] D. Perrone, E. Brunesi, A. Filiatrault, and R. Nascimbene, "Probabilistic estimation of floor response spectra in masonry infilled reinforced concrete building portfolio," Engineering Structures, vol. 202, Article ID 109842, 2020.

[48] P. M. Clvi and T. J. Sullivan, "Estimating floor spectra in multiple degree of freedom systems," Earthq Struct, vol. 7, no. 1, pp. 17-38, 2014.

[49] V. Vukobratović and P. Fajfar, "Code-oriented floor acceleration spectra for building structures," Bulletin of Earthquake Engineering, vol. 15, pp. 3013-3026, 2017.

[50] Y. Xiao and H. W. Yun, "Testing of full-scale concrete and clay tile roof models," Journal of Structural Engineering, vol. 124, pp. 482-489, 1998.

[51] S. M. Takhirov, A. Gilani, and L. Tedesco, "Seismic testing of nonstructural components and assessment of the prescribed response spectrum," in Proceedings of the 10th US National Conference on Earthquake Engineering, Frontiers of Earthquake Engineering, Anchorage, AK, USA, July 2014.

[52] S. L. Lin, G. A. MacRae, R. P. Dhakal, and T. Z. Yeow, "Building contents sliding demands in elastically responding structures," Engineering Structures, vol. 86, pp. 182-191, 2015.

[53] C. Mathey, C. Feau, D. Clair, L. Baillet, and M. Fogli, "Experimental and numerical analyses of variability in the responses of imperfect slender free rigid blocks under random dynamic excitations," Engineering Structures, vol. 172, pp. 891-906, 2018.

[54] D. D’Angela, G. Magliulo, and E. Consenza, "Towards a reliable seismic assessment of rocking components," Engineering Structures, vol. 230, Article ID 111673, 2021.

[55] Standards New Zealand (SNZ), Structural Design Actions, Part 5: Earthquake Actions, NZS 1170.5, Wellington, New Zealand, 2004.

[56] W. Lu, B. Huang, S. Chen, and K. M. Mosalam, “Acceleration demand of the outer-skin curtain wall system of the Shanghai Tower," Struct Des Tall Spec, vol. 26, 2017.

[57] International Conference of Building Officials (ICBO), Uniform building code, International Conference of Building Officials, Whittier, CA, USA, 1997.

[58] R. Drake and R. Bachman, "Interpretation of instrumented building seismic data and implications for building codes," in Proceedings of the 64th Annual Convention of the Structural Engineers Association of California, Structural Engineers Association of California, Indian Wells, CA, USA, October 1995.

[59] R. Drake and R. Bachman, "NEHRP provisions for 1994 for nonstructural components," Journal of Architectural Engineering, vol. 2, pp. 26-31, 1996.

[60] S. Fathali and B. Lizundia, "Evaluation of current seismic design equations for nonstructural components in tall buildings using strong motion records," Struct Des Tall Spec, vol. 20, no. S1, pp. 30-46, 2011.

[61] Ministry of Housing and Urban-rural of the People's Republic of China (MHURD), Code for Seismic Design of Buildings (GB 50011-2010), China Architecture \& Building Press, Beijing, China, 2016, in Chinese.

[62] B. Huang, W. Lu, and W. Cao, "Discussion on the seismic performance indices of architectural curtain wall," China Civil Engineering Journal, vol. 42, pp. 7-12, 2009, in Chinese.

[63] C. Chen and S. A. Mahin, Performance-Based Seismic Demand Assessment of Concentrically Braced Steel Frame Buildings,
Report No. PEER 2012/103, Pacific Earthquake Engineering Research Center, Berkeley, CA, USA, 2012.

[64] Math Works, "Matlab, R2012a," 2012.

[65] M. E. Ahmad, "Seismic performance evaluation of modern bare and masonry-infilled RC SMRF structures," Advances in Civil Engineering, vol. 2019, Article ID 6572465, 15 pages, 2019.

[66] G. Lee and C. H. Loh, Eds., The Chi Chi, Taiwan Earthquake of September 21, 1999: Reconnaissance Report, Technical Report MCEER-00-0003, University of Buffalo, New York, NY, USA, 2000.

[67] R. Assi, G. McClure, and G. C. Yao, "Floor acceleration demands for 11 instrumented buildings in Taiwan during the 1999 Chi Chi earthquake," in Proceedings of the Structures Congress, pp. 1-11, ASCE, New York, NY, USA, April 2005.

[68] Y. Hisada, T. Yamashita, and M Murakami, "Seismic response and damage of high-rise buildings in Tokyo, Japan, during the 2011 Tohoku earthquake," in Proceedings of the 15th World Conference on Earthquake Engineering, Lisboa, Portugal, September 2012.

[69] T. Kubo, Y. Hisada, K. Aizawa, K. Omiya, and S. Koizumi, "Investigation of indoor damage and questionnaire intensity for high-rise building in Tokyo during the great east Japan earthquake," Japan Association for Earthquake Engineering, vol. 14, pp. 118-141, 2014.

[70] B. Ellingwood, Ed., An Investigation of the Miyagi-Ken-Oki, Japan, Earthquake of June, 12, 1978, NBS (National Bureau of Standards) Special Publication, Gaithersburg, MD, USA, 1980.

[71] M. Çelebi, I. Okawa, and T. Kashima, "March 11, 2011 M=9.0 Great East Japan earthquake: the story of a retrofitted building damaged and repaired," in Proceedings of the 15th World Conference on Earthquake Engineering (15WCEE), Lisboa, Portugal, September 2012.

[72] R. P. Dhakal, "Damage to Non-structural components and contents in 2010 Darfield earthquake," Bulletin of the New Zealand Society for Earthquake Engineering, vol. 43, pp. 404-411, 2010.

[73] A. Baird, A. S. Tasligedik, A. Palermo, and S. Pampanin, "Seismic performance of vertical nonstructural components in the 22 February 2011 Christchurch earthquake," Earthquake Spectra, vol. 30, pp. 401-425, 2014.

[74] B. J. Goodno, N. C. Gould, P. Caldwell, and P. L. Gould, "Effects of the january 2010 Haitian earthquake on selected electrical equipment," Earthquake Spectra, vol. 27, no. S1, pp. S251-S276, 2017.

[75] D. Perrone, P. M. Calvi, R. Nascimbene, E. C. Fischer, and G. Magliulo, "Seismic performance of non-structural elements during the 2016 Central Italy earthquake," Bulletin of Earthquake Engineering, vol. 17, pp. 5655-5677, 2019.

[76] Federal Emergency Management Agency (Fema), Reducing the Risks of Nonstructural Earthquake Damage-A Practical guide. FEMA E-74, Federal Emergency Management Agency, Washington, DC, USA, 2012.

[77] R. K. Goel and A. K. Chopra, "Period formulas for momentresisting frame buildings," Journal of Structural Engineering, vol. 123, pp. 1454-1461, 1997.

[78] R. K. Goel and A. K. Chopra, "Period formulas for concrete shear wall buildings," Journal of Structural Engineering, vol. 124, pp. 426-433, 1998.

[79] O. S. Kwon and E. S. Kim, "Evaluation of building period formulas for seismic design," Earthquake Engineering \& Structural Dynamics, vol. 39, pp. 1569-1583, 2010. 
[80] K. Porter, R. Kennedy, and R. Bachman, "Creating fragility functions for performance-based earthquake engineering," Earthquake Spectra, vol. 23, pp. 471-489, 2007.

[81] S. Günay and K. M. Mosalam, "PEER performance-based earthquake engineering methodology, revisited," Journal of Earthquake Engineering, vol. 17, pp. 829-858, 2013.

[82] A. Filiatrault, D. Perrone, R. J. Merino, and G. M. Calvi, "Performance-based seismic design of nonstructural building elements," Journal of Earthquake Engineering, vol. 25, 2018. 